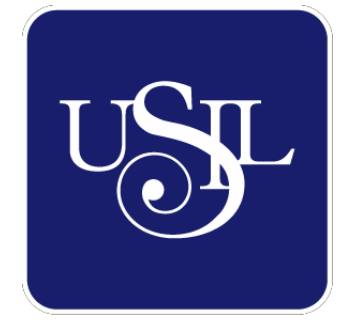

UNIVERSIDAD

SAN IGNACIO

DE LOYOLA

FACULTAD DE HUMANIDADES

Carrera de Psicología

\title{
ACTITUD HACIA EL USO DE LAS TICS Y DESEMPEÑO AUTOPERCIBIDO EN DOCENTES DE LIMA EN CONFINAMIENTO POR COVID-19
}

Tesis para optar el Título Profesional de Licenciado en Psicología

KARINA CHOQUECOTA QUINTA (0000-0002-0172-361X)

ESCARLE JOMEINE QUISPE LIVIAS (0000-0002-7019-9356)

Asesora:

Mg. Carmen Magali Meléndez Jara

(0000-0003-1446-4837)

Lima - Perú 2021 
DEDICATORIA

Con amor y gratitud a nuestros padres. 


\section{Resumen}

La presente investigación tuvo como objetivo relacionar la actitud hacia el uso de las TICs y el desempeño autopercibido en docentes de Lima en confinamiento por COVID-19. La muestra estuvo compuesta por 69 docentes de Educación Básica Regular de Lima Metropolitana (78.3\% mujeres) con edades comprendidas entre 24 y 63 años $(M=45.3, D E=9.44)$. Se usó la Escala de actitud: uso de Tecnologías de Información y Comunicación (TIC) en la enseñanza, compuesta por tres dimensiones actitudinales: cognitivo, afectivo y conductual. Para medir desempeño docente se usó el Autoreporte del desempeño docente que contiene tres dimensiones: evaluación del desempeño en el aula, autoevaluación de las labores en el ámbito escolar e interacción con los alumnos. Los resultados evidencian una moderada, positiva y significativa relación entre la actitud hacia el uso de las TICs y evaluación de desempeño en el aula $(r=.70 ; p<.05)$ e interacción con los estudiantes $(r=.51 ; p<.05)$, por el contrario, no se evidenció una relación positiva entre la actitud hacia el uso de las TICs y la autoevaluación de las labores escolares $(r=-.42 ; \mathrm{p}<.05)$, asimismo con sus dimensiones. Se concluyó la existencia de una asociación baja entre la actitud hacia el uso de las TICs y el desempeño autopercibido en docentes, quienes han laborado en confinamiento por COVID-19 durante el periodo escolar 2020.

Palabras claves: actitud hacia el uso de TICs, confinamiento, desempeño docente. 


\begin{abstract}
The sample consisted of 69 teachers of Regular Basic Education of Metropolitan Lima (78.3\% women) with ages between 24 and 63 years $(\mathrm{M}=45.3, \mathrm{SD}=9.44)$. The Attitude Scale was used: use of Information and Communication Technologies (ICT) in teaching, composed of three attitudinal dimensions: cognitive, affective and behavioral. To measure teacher performance, the Self-report of teacher performance was used, which contains three dimensions: performance evaluation in the classroom, self-evaluation of tasks in the school environment and interaction with students. The results show a moderate, positive and significant relationship between the attitude towards the use of ICTs and performance evaluation in the classroom $(\mathrm{r}=.70 ; \mathrm{p}<.05)$ and interaction with students $(\mathrm{r}=.51 ; \mathrm{p}<.05)$, on the contrary, there was no evidence of a positive relationship between the attitude towards the use of ICTs and the self-evaluation of schoolwork $(r=-.42 ; p<.05)$, also with its dimensions. The existence of a low association between the attitude towards the use of ICTs and the selfperceived performance of teachers, who have worked in confinement for COVID-19 during the 2020 school period, was concluded.
\end{abstract}

Keywords: attitude towards the use of ICTs, confinement, teaching performanc 
Tabla de Contenido

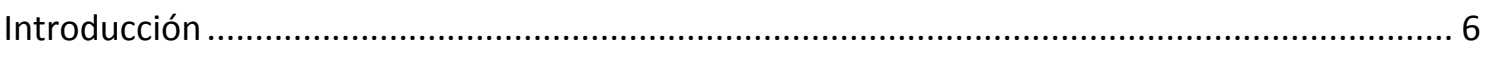

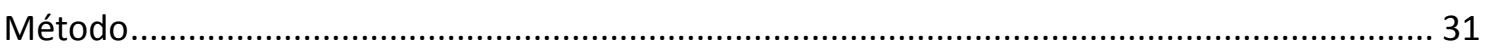

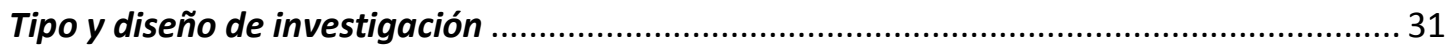

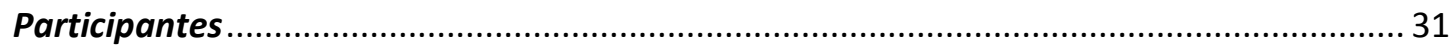

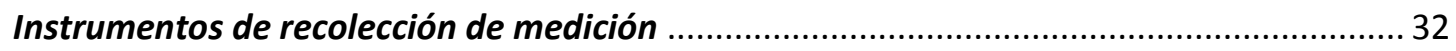

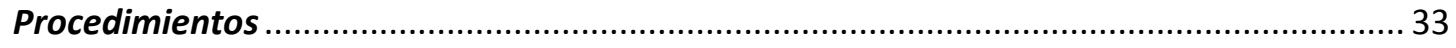

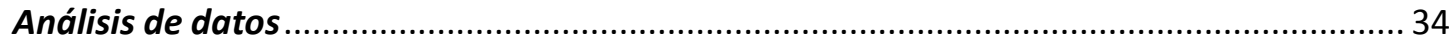

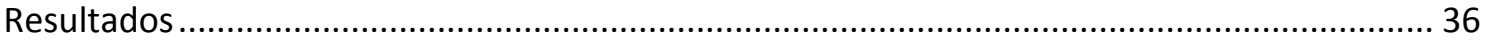

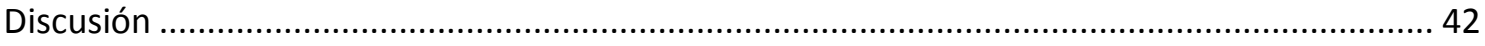

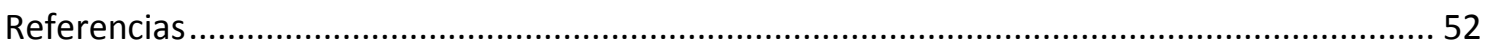

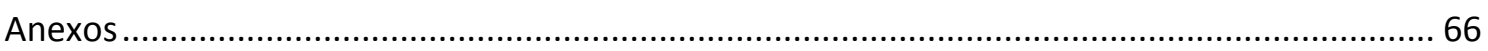

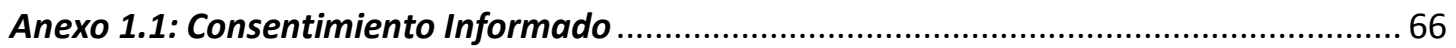

Anexo 1.2: Ficha sociodemográfica 67

Anexo 1.3: Escala actitud del uso de las Tecnologías de Información y Comunicación (TIC)

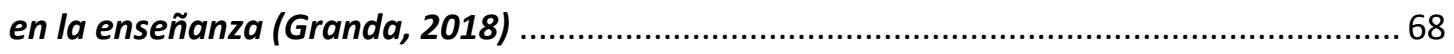

Anexo 1.4: Cuestionario de autorreporte del desempeño docente (Fernández, 2002)........ 70 


\section{Índice de tablas}

Tabla 1. Análisis descriptivos de las variables de estudio

Tabla 2. Niveles de actitud hacia el uso de las Tics en docentes de Lima Metropolitana 37

Tabla 3. Desempeño autopercibido en docentes de Lima Metropolitana..... 388

Tabla 4. Desempeño autopercibido en docentes de Lima Metropolitana .................................40 


\section{Introducción}

La Organización Mundial de la Salud [OMS] (2020), anunció el 31 de diciembre de 2019 la aparición de la epidemia por Coronavirus (COVID-19) en Wuhan (China); el 30 de enero de 2020 la OMS declaró que el brote de COVID -19 conformaba una pandemia, por lo que se tomaron medidas preventivas en la mayoría de los países del mundo, tomando como primera acción el inicio de periodo de distanciamiento humanosocial, provocando una crisis interna en diferentes sectores, siendo uno de estos el sector educativo (Pérez \& Tramallino, 2020). Por consiguiente, más de 190 países cerraron masivamente las actividades presenciales de instituciones educativas. Según el informe de las Naciones Unidas para la Educación, la Ciencia y la Cultura (UNESCO), señaló que a mediados de mayo 2020 más de 1.200 millones de estudiantes, en todo el mundo, dejaron de tener clases presenciales, siendo de América Latina y el Caribe más de 160 millones estudiantes (Comisión Económica para América Latina y Caribe [CEPAL], 2020).

No obstante, se determinó un régimen de educación a distancia (on-line) a consecuencia del cierre de la mayoría de las instituciones educativas alrededor del mundo, siendo un gran reto para los docentes el manejo de sesiones sincrónicas y asincrónicas de manera virtual (Cáceres, 2020), así como el uso de diferentes herramientas y aplicaciones de videollamadas disponibles como el Zoom, Google Classroom, Skype, WhatsApp, Facebook, entre otros. Estas herramientas tecnológicas presentan distintas funcionalidades permitiendo el logro de diferentes objetivos educativos, teniendo en cuenta el contexto presentado (García, 2020).

En Perú, el 6 de marzo del 2020, el expresidente de la República, Martín Vizcarra Cornejo, confirmó el primer caso de COVID-19. A partir de ello, el Ministerio de Salud 
(MINSA) hizo un llamado a la calma y recomendó a la población mantener las medidas de control sanitaria. Así mismo, el exmandatario y el Consejo de Ministros aprobaron un decreto de urgencia que dispuso las medidas necesarias para enfrentar la propagación del virus COVID-19 en territorio nacional (Diario Gestión, 2020). La implementación de estas medidas para combatir el COVID-19 establecieron la reorganización en los sistemas: de salud, educativo, económico y social.

Como primera medida preventiva de salud, el 12 de marzo el Ministerio de Educación (MINEDU) indicó la suspensión del servicio educativo hasta el 29 de marzo del 2020 en centros educativos públicos y la reprogramación de horas lectivas en centros educativos privados (quienes ya habían iniciado sus clases), sustentando así la necesidad de reorganizar la estructura de la Norma Técnica: Orientaciones para el desarrollo del Año Escolar 2020 en las instituciones Educativas y Programas Educativos de la Educación Básica (Resolución Viceministerial N 079, 2020). Así mismo, el 13 de marzo se aprueba la Norma Técnica: Disposiciones para la adquisición de equipamiento menor (Kits de Higiene) en el marco del Programa de Mantenimiento de locales educativos 2020 (Resolución Ministerial $\mathrm{N}^{\circ}$ 149, 2020), mejorando las condiciones de salubridad y protección para los docentes y estudiantes en las instituciones educativas, con miras al inicio del año escolar de manera presencial (Ravines, 2020).

El 15 de marzo del 2020, el ex-presidente Martín Vizcarra Cornejo, declaró al país en Estado de Emergencia Nacional; convirtiéndose en el primer país de América Latina en decretarla; por las graves circunstancias que afectaban la salud de la población; estableciendo medidas excepcionales de prevención ante la posible propagación del COVID-19 en territorio peruano (Lechleiter \& Vidarte, 2020), por lo que el 16 de marzo del 2020 se dio inició al aislamiento social obligatorio el cual finalizaba el 30 de marzo, 
periodo en el que se garantizaba de manera presencial sólo el abastecimiento de alimentos, medicinas, saneamiento, servicios de agua, luz eléctrica, telecomunicaciones, limpieza, recojo de residuos sólidos y servicios funerarios (Diario El Peruano, 2020). Esta situación obligó al MINEDU a disponer del cierre temporal de todas las instituciones educativas tanto públicas como privadas; en sus diferentes niveles, etapas y modalidades; impactando así en la educación de 9.9 millones de estudiantes y docentes quienes no pudieron reunirse en sus centros educativos (Lechleiter \& Vidarte, 2020).

Por lo mencionado anteriormente, se adaptaron de manera urgente y sin precedentes, propuestas y medidas más adecuadas para evitar la pérdida del año escolar frente a la emergencia sanitaria, las cuales implicaban el mantenimiento del distanciamiento social. Una de las propuestas del MINEDU fue iniciar las clases el 6 de abril de 2020 a través de la estrategia “Aprendo en casa” lo que llevó a docentes y estudiantes migrar de una educación presencial a una educación a distancia o remota a través de medios como radio, televisión y diversas plataformas de internet, siendo estos medios complementarios y temporales hasta el reinicio del formato presencial una vez controlada la pandemia (Resolución Ministerial, N 160, 2020).

Esta nueva forma de enseñanza en tiempos de pandemia por COVID-19, presentó un gran reto pedagógico para docentes quienes por años han trabajado de forma presencial en las aulas. Actualmente, se les exigen recursos, capacidades, habilidades y competencias que (los docentes) debieran poseer y que no han sido, necesariamente, parte de su formación profesional, pues su presente práctica pedagógica de forma remota se relaciona con el uso de tecnologías digitales, búsqueda de estrategias de comunicación sincrónica y asincrónica, diseño de tareas que fomenten el aprendizaje autónomo y nuevos formatos de evaluación del logro de los aprendizajes en los estudiantes (evidencias). 
Sumado a ello, los docentes requieren de un buen desempeño y adecuada gestión de su tiempo, ya que se presenta una sobrecarga de trabajo por el incremento y complejización de tareas, además de la necesidad de estar disponible a toda hora; antes, durante y después de una sesión remota, en la que deben acompañar, atender y resolver cualquier duda o dificultad que surja en los estudiantes sobre el ingreso a las plataformas, desarrollo de temas correspondientes y ejecución de tareas; además de realizar las correcciones de las evidencias que les envían estos (Socolovsky, 2020).

A su vez, los docentes asumen presiones familiares y personales derivadas del confinamiento y sobrecarga laboral por una enseñanza virtual como: la convivencia familiar, el compartimiento de espacios comunes para la familia y el trabajo, adaptación de nuevas rutinas o hábitos, dificultades económicas, de salud, sociales y afectivas. Dentro de la esfera psicoafectiva se evidencian cambios emocionales como: incertidumbre debido a no saber con exactitud lo que puede suceder con su trabajo y si los estudiantes alcanzarán los objetivos y logros planteados al finalizar el año escolar (Cabrera, 2020), sentimientos de tristeza o apatía generada por la cantidad de noticias negativas de pandemia, frustración al no contar con la información necesaria para la toma de decisiones, ansiedad debido al descontrol de diversas situaciones dentro de una sesión virtual, que ya no están bajo su control: el miedo y el cansancio, debido a que el horario de trabajo se ha extendido por las circunstancias de pandemia (Mazza, 2020; Sánchez, et. al, 2020).

Frente a estas circunstancias, los docentes desarrollaron; como factor clave dentro de su rol; la resiliencia generativa, vinculada con la capacidad de experimentar situaciones adversas (pandemia) como una oportunidad de crecimiento y desarrollo, al generar alternativas de solución frente a las condiciones de la emergencia sanitaria (Román et al, 
2020). Es así como los docentes han hecho uso de las diversas herramientas y plataformas tecnológicas e informáticas para no detener la formación de sus estudiantes; afianzando y mostrando de esta manera su verdadera vocación. Se reporta que un considerable número de docentes crean y difunden material extra y lo socializan en plataformas de audio y video populares (Youtube, WhatsApp y Facebook) asimismo aprendieron a evaluar en línea a través de exámenes virtuales, reprogramaron clases a quienes faltaron o no lograron comprender el tema, entre otras actividades (Diario El Peruano, 2020).

Por lo expuesto, se buscará determinar si, ¿existe relación entre la actitud hacia el uso de las TICs y el desempeño autopercibido en docentes de Lima en confinamiento por COVID-19?

En tal sentido, se abordará teóricamente las variables de estudio actitud hacia el uso de las TICs y el desempeño autopercibido docente.

Actitud docente y nuevas tecnologías de la información y comunicación.

Myers (2000) define a la actitud como una reacción evaluativa favorable o desfavorable hacia alguien o algo, que se manifiesta en las creencias, los sentimientos o el comportamiento deliberado. Asimismo, Worchel, Cooper, Goethals y Olson (2002) señalan que la actitud es un juicio evaluativo (bueno o malo) de un objetivo, por lo que representa una tendencia favorable o negativa del individuo hacia este.

Zimbardo y Leippe (1991) se refieren a la actitud como una disposición evaluativa sobre un objeto, basado en conocimientos, reacciones o intenciones afectivas $\mathrm{y}$ comportamentales que influyen en los conocimientos, respuestas afectivas y comportamientos futuros. 
Por su parte, Whittaker y Sandra (1986) señalan que las actitudes presentan las siguientes características:(1) son aprendidas ya que son producto de experiencias obtenidas en un ambiente social-cultural que influyen en el comportamiento del sujeto; (2) estables a pesar de ello pueden ser modificadas, (3) tienen dirección, pueden ser favorables o desfavorables. (4) Implican relaciones entre objeto y sujeto debido a que guardan predisposiciones permanentes de alguien (sujeto) hacia algo o contra algo específico (objeto). (5) Pueden referirse a un objeto, a un pequeño número de objetos o a un gran número de ellos. Las actitudes se expresan a partir de cómo y qué se dice, de cómo se responde a través de: gestos, expresiones faciales, postura del cuerpo y tono de voz.

En cuanto a la relación de las actitudes con las TICs, Bolívar (2012) señala que toda actitud docente dirigida a las TICs puede ser entendida como una disposición aprendida, más o menos permanente, expresada en términos de creencias, sentimientos y tendencia a la acción hacia las mismas.

Asimismo, el autor agrega tres tipos de representación de las actitudes docentes hacia las TICs: (1) actitud favorable integrada por el entusiasmo sobre su uso e involucramiento de manera activa con el mismo. (2) Actitud neutra está representada por un interés medio y un entusiasmo bajo incentivos y circunstancias apropiadas. (3) Actitud desfavorable está formada por sentimientos de inutilidad al uso de las TICs, creencias sobre una baja prioridad y que no vale la pena hacer esfuerzos al respecto.

Naranjo (2010) señala que existen dos formas de adquirir actitudes: (1) el modo directo, cuando es obtenido mediante su propia experiencia, produciendo en la persona satisfacción y significado; (2) el modo indirecto, es adquirida a través de la identificación 
sobre alguien basado en el respeto y admiración, quienes se convierten en modelos auténticos.

Por su parte, para Oskamp (1991) y Cubas (2007) existen cinco factores determinantes de las actitudes: (1) factor fisiológico y genético a las predisposiciones generales para el futuro desarrollo de determinadas actitudes. (2) La experiencia personal directa es uno de los primeros factores y el más importante debido a que las personas obtienen mayor conocimiento a partir de sus experiencias personales, siendo más confiables que la información recibida por otras personas. Asimismo, en personas más resistentes al cambio, este factor ejerce una mayor y rápida influencia en su conducta. (3) La influencia de los padres durante los primero años ya que se tiene mayor control sobre sus primeras experiencias (p.e. conversaciones y observaciones de las interacciones padres-hijos). (4) Influencia o presión de los grupos como los pares (compañeros de colegio), de los grupos de referencia, etc. (5) Finalmente los medios de comunicación debido a que desarrolla en los niños actitudes favorables hacia objetos. Sin embargo, muchas veces los medios de comunicación brindan a los niños información que deberían conocer y que no necesariamente se les da en casa o en el colegio.

En el campo educativo, Meléndez-Ferrer y Canquiz (2003) agregan que la actitud docente implica un acto reflexivo, lo cual le permite hacer una crítica constructiva sobre la labor que desempeña como profesional de la educación y en su interacción con las TICs, siendo en la actualidad de uso constante, denotando una actitud positiva como lo evidenciaron Konca, Ozel y Zelyurt (2016) quienes evaluaron a 103 profesores de nivel inicial en las ciudades de Kirsehir y Malatya de Turquía durante el semestre académico 2014-2015 encontrando que el 90,26\% de los profesores tiene una actitud alta y el 8,745\% una actitud moderada hacia el uso de herramientas tecnológicas y materiales. A diferencia 
de éstos Mendoza y Lukis (2020) que evaluaron las actitudes de 177 docentes universitarios en el uso de las TICs durante su ejercicio profesional, encontraron una actitud desfavorable hacia estas debido a que el cambio hacia la tecnología afectó su integración laboral, además el acceso a las TICs y el soporte para su uso no es brindado eficientemente y esto afectaría su desempeño; la percepción también se torna negativa, sin embargo se reportan actitudes favorables cuando la finalidad es introducir estas estrategias para enriquecer el proceso educativo, el desempeño docente y la participación activa de los estudiantes.

\section{Modelos de las actitudes}

De acuerdo con Sánchez y Mesa (1997) el Modelo Unidimensional consiste en destacar el componente evaluativo de la actitud, de tal manera se pueda referir a un sentimiento general, permanentemente positivo o negativo hacia alguna persona, objeto o problema. Por lo cual, la actitud representa las emociones relacionadas con el objeto de actitud, es decir su evaluación positiva o negativa.

Por otro lado, Sánchez y Mesa (1997) proponen el Modelo de los Tres Componentes compuesto por una triple clasificación en toda actitud y su relación entre sí, siendo estos: (1) el componente cognitivo que está conformado por creencias, conocimientos, opiniones, información u otros, relativos al objeto de actitud. (2) El componente afectivo que expresa sentimientos de aceptación, gusto, rechazo o ansiedad hacia el objeto de actitud asimismo este componente define el sentimiento a favor o en contra de un determinado objeto social. (3) Y finalmente el componente conativo o conductual que incluye actos y conductas que el individuo manifiesta en presencia del objeto de actitud. 
Competencias digitales y tecnologías de información y comunicación (TIC)

Es indispensable para los docentes desarrollar competencias digitales, que les permitan desenvolverse mejor frente a las TIC y responder con eficacia los nuevos retos educativos. Asimismo, Vilcahuamán (2019) define las competencias digitales como "un conjunto de habilidades, capacidades, destrezas, conocimientos y actitudes que permitan desempeñarse de forma eficiente frente a cualquier situación de trabajo" (p. 19).

Para Calvani, Cartelli, Fini y Ranieri (2008) la competencia digital consiste en la capacidad de explorar y enfrentar situaciones tecnológicas de manera flexible; seleccionando, analizando y evaluando críticamente los datos, información y potencial tecnológico con el fin de resolver problemas y construir conocimiento” (p. 186).

Respecto a las tecnologías de información y comunicación, Tello (2011) establece que las TICs son un conjunto de herramientas usadas para almacenar, crear, intercambiar y procesar información en sus distintas formas (datos, mensajes, imágenes fijas o en movimiento, presentaciones multimedia, entre otras). Por su parte Gil (2002) define a las TICs como un conjunto de aplicaciones, sistemas, herramientas, técnicas y metodologías asociadas a la digitalización de señales analógicas, sonidos, textos e imágenes, manejables en tiempo real.

Cruz, Pozo, Aushay y Arias (2018) afirman que las TICs son un banco esencial de herramientas que facilitan el intercambio de conocimientos entre docente y estudiante, lo que sugiere una nueva aplicación pedagógica orientada a la curiosidad y motivación de cada estudiante, debido a que el docente no es quien gesta el conocimiento, sino es una guía hacia el futuro educativo.

En cuanto a su funcionalidad, Rosario (2005) plantea que estas permiten adquirir, producir, almacenar, tratar, comunicar, registrar y presentar información auditiva (a partir 
de llamadas, mensajes de voz) y visual (imágenes), contenidos en señales de naturaleza acústica, óptica o electromagnética.

Por su parte, Cabero (1996) caracteriza a las TICs con las siguientes propiedades: a) Inmaterialidad: la materia prima es la información, así como generar y procesar información. Asimismo, De Pablos (2010) señala que toda la información se puede localizar, exponer, intercambiar, transferir, recibir, vender o comprar en cualquier momento, en tiempo real. b) Interactividad: permite la interacción total del sujeto con la máquina, por lo tanto, es ilimitada. c) Instantaneidad: facilita la rapidez de acceso e intercambio de la información. d) Innovación: se busca la mejora, el cambio, así como incorporar y asimilar nuevas tecnologías con el pasar del tiempo. e) Calidad de imagen y/o sonido: lo que da fiabilidad y fidelidad a la información transferida. f) Interconexión: aunque se presentan de forma independiente, pueden combinarse y ampliar sus conexiones. g) Diversidad: las TIC desempeñan muchas funciones ya sea almacenar información hasta la interacción entre usuarios, además esta diversidad se puede multiplicar si se implementan nuevos hardware (cámara, GPS, etc.), por ejemplo, el Smartphone, ya que el número de sus aplicaciones aumenta exponencialmente.

De esta manera, las TICs crean un entorno de enseñanza que facilita a docentes y estudiantes a formarse de manera asincrónica, ofreciéndoles el poder elegir, respecto a dónde, cómo y cuándo estudiar, favoreciendo un proceso de aprendizaje individual, a su propio ritmo y circunstancias (Cabero, 2002).

Estas tecnologías se vienen incorporando en diversas áreas del conocimiento, generando grandes oportunidades de cambio y desafíos en cuanto a su adaptación, tanto así que su papel; en la actualidad; es fundamental para el avance de la educación y sociedad; ya que su utilización repercute en la vida del ser humano. Para ello, su 
aplicación exige una actualización elocuente del sistema que acorte la brecha de la formación educativa en la sociedad (Hernández, 2017; Ormaza \& Rodríguez, 2020).

Bajo esta mirada, la plataforma educativa Blink Learning (2019) señala que se presentan desafíos durante la introducción de las TIC en la educación, planteando los siguientes:

a) Problemas de conectividad.

b) Formación del profesorado (manejo de dispositivos electrónicos, uso de aplicaciones, tiempo y recursos para formarse, etc.).

c) Formación del alumnado (uso de la tecnología más allá de fines sociales o recreativos).

d) Carencia de dispositivos suficientes para todos los alumnos y/o docentes.

e) Medios para controlar que los estudiantes utilizan sus dispositivos para seguir la clase y no con otros fines.

f) Usabilidad de los contenidos digitales (estabilidad, navegabilidad intuitiva, optimización de los recursos, etc.).

g) Adaptación del proceso de aprendizaje educativo al uso de la tecnología.

h) Desconfianza o rechazo de las familias comunidad educativa.

i) Seguridad y protección de datos.

Frente a estos desafíos, un estudio realizado a 409 docentes en el Perú reportó que el principal reto que presentaron en la introducción de las TIC en los centros educativos fue: la formación del profesorado con un $60 \%$, seguido por la carencia de dispositivos suficientes $44 \%$ y problemas de conectividad $40 \%$ (Blink Learning, 2019). De los aspectos mencionados, según Rosales (2014) la actitud de los docentes frente al uso de las TIC juega un papel importante para mejorar el proceso de enseñanza-aprendizaje, y será determinante su actualización y el conocimiento que tenga con respecto al tema. Finalmente, la actitud del docente puede aumentar en la medida en que tenga el 
conocimiento teórico y práctico sobre las TICs y además posea recursos necesarios dentro de la institución educativa en la que labore y esté capacitado para utilizarlos.

\section{Las TIC de uso más frecuente en la educación durante la pandemia}

Desde la declaración de la pandemia por Covid-19, la interacción en las plataformas sociales ha crecido significativamente en todo el mundo. Shum (2020) basado en los estudios del Informe Digital 2020 Global Statshot de julio publicado en asociación con We Are Social \& Hootsuite, revela que hay 4.57 mil millones de usuarios en internet a nivel mundial, en comparación al mes de enero (4.54 mil millones). Asimismo, se hallaron 3.96 mil millones de usuarios activos en redes sociales, a diferencia al inicio del año 2020 (3.80 mil millones) y la cantidad de usuarios de teléfonos móviles es de 5.15 mil millones. Asimismo, el autor señala que las plataformas más usadas en el mundo son las siguientes:

- Facebook con 2603 millones de usuarios activos (tuvo un aumento del 6.3\%).

- YouTube mantiene los 2000 millones de usuarios.

- WhatsApp tiene 2000 millones de usuarios activos (tuvo un crecimiento del 25\%).

- Facebook Messenger mantiene los 1300 millones de usuarios activos.

- WeChat tiene actualmente 1203 millones usuarios activos (crecimiento del 4.5\%).

- Instagram tiene 1082 millones de usuarios activos (tuvo un crecimiento el 8.2\%).

- TikTok tiene 800 millones de usuarios activos.

- QQ tiene 694 millones de usuarios activos (tuvo una disminución del 5\%).

- Sina Weibo tiene 550 millones de usuarios activos (crecimiento de 10.6\%).

- Qzone tiene 517 millones de usuarios activos (no tuvo cambio).

- Reddit tiene 430 millones de usuarios activos (no tuvo cambio).

- Kuaishou tiene unos 400 millones de usuarios activos (aumento de casi 27\%).

- Douyin tiene 400 millones de usuarios activos. 
- Snapchat tiene 397 millones de usuarios activos (tuvo un crecimiento de 3.9\%).

- Pinterest tiene 367 millones de usuarios activos (tuvo un aumento de casi 14\%).

- Twitter tiene 326 millones de usuarios activos (tuvo una disminución de 4.11\%).

Además, Shum (2020) sostiene que las herramientas de videoconferencia fueron las mejores aliadas en esta pandemia, debido a su facilidad y las diversas funciones que se encuentran dentro de ellas, por lo que las plataformas más usadas para realizar las videoconferencias fueron:

- Cisco Webdex tiene alrededor de 500 millones de asistentes mensuales.

- Zoom tiene alrededor de 300 millones de participantes por día.

- Google meet tiene alrededor de 100 millones de participantes por día.

- Microsoft Team tiene alrededor de unos 75 millones de usuarios activos.

- Skype tiene alrededor de unos 40 millones de usuarios activos).

Diario Gestión (2020) menciona que, en el Perú, las TICs de mayor uso durante la pandemia se relacionan con el servicio de videollamadas o videoconferencia como: Google Meet con un $21 \%$ y Zoom en un $10 \%$, las cuales han presentado un incremento sorprendente en tan poco tiempo.

La UNESCO (2020) ha realizado una clasificación de Tics de acuerdo con su funcionalidad durante la pandemia en el contexto educativo, entre ellas tenemos: (1) sistemas de gestión de aprendizaje (Google Classroom, Edmodo, Comunidad TU CLASE y Moodle); (2) herramientas digitales para impartir clases a distancia (Google Meet, YouTube Studio, Zoom, Skype y Jitsi Meet); (3) y herramientas digitales de comunicación (WhatsApp, Slack, Gmail - Hangouts). 


\section{Desempeño docente}

Para Fernández en 2002, el desempeño docente es entendido como un conjunto de acciones que llevan a cabo diariamente en su ejercicio profesional, el cual consiste en la preparación de clases, clasificación de los trabajos asignados, las coordinaciones con otros docentes y con la directiva del plantel, así como la participación en programas de capacitación.

Cherry (2016) citado por Ludeña (2019) manifiesta que el desempeño docente está determinado por un conjunto de factores que son propios de docentes, estudiantes y entorno. De acuerdo con Espinosa (2014) existen seis factores que influyen en el desempeño docente: 1) Formación inicial y capacitación docente: iniciada al ingresar a una institución de educación superior pedagógica que provee de un aprendizaje necesario para la perfección en sus competencias cognitivas y técnicas. Asimismo, la preparación del docente para su desempeño dentro o fuera de su trabajo mediante programas de capacitación. 2) Motivación: constituida por aquellos factores capaces de provocar, mantener y dirigir la conducta de las personas hacia un objetivo o fin. Para Caballero (2003) la motivación es la incentivación por la que las personas actúan buscando satisfacer ciertos fines o necesidades. 3) Relación profesor-estudiante: El maestro debe construir un ambiente apropiado y cálido, mediante la formación de valores como: comprensión, tolerancia, respeto y armonía, sin descuidar el control y el manejo de la disciplina de los estudiantes. 4) Relación familia-escuela: Teniendo en cuenta que la educación es una tarea compartida entre padres y educadores; ambos sistemas (familia y escuela) son indispensables para el establecimiento de relaciones cordiales, constructivas, fluidas y complementarias, que optimizan el adecuado desarrollo y crecimiento infantil. 5)Organización institucional: Dentro de las organizaciones existen situaciones que pueden afectar la práctica docente, por ello es fundamental mantener líneas de 
comunicación, que respeten los vínculos y estructura jerárquica entre sus integrantes. 6) Políticas educativas: Son importantes las leyes y acciones que emprenda un gobierno respecto a las prácticas educativas, además de garantizar a todos los docentes la estabilidad laboral, la actualización y la formación continua a través de cursos, seminarios, talleres y otras capacitaciones a nivel pedagógico y académico. Además de ofrecer a los educadores mejoras en su remuneración acorde con su grado de profesionalismo y responsabilidades.

\section{Evaluación del desempeño docente}

Valdés (2006) citado por Saravia (2019) afirman que la evaluación del desempeño docente es un método sistemático en el que se recaba información valedera, con el propósito de conocer el impacto educativo que produce en los estudiantes, ello relacionado a la exhibición de sus competencias pedagógicas, responsabilidad laboral, emocionalidad y la relación que mantiene con los estudiantes, padres, directivos, colegas entre otros.

Lino (2018) sostiene que "las evaluaciones docentes están estructuradas para poder reflejar los logros y las deficiencias del proceder del docente, este tipo de evaluaciones permite determinar las direcciones fundamentales en las cuales se debe trabajar" (p.28). Por lo que, el autor infiere que la evaluación del desempeño docente, debe establecer estrategias de observación, consulta, encuestas, resultados motivacionales, resultados académicos del alumnado, así como del desenvolvimiento del docente desde que inicia la preparación de contenidos utilizando los recursos disponibles de TIC, hasta la transmisión de conocimientos al estudiante, puesto que el objetivo final es que el estudiante adquiera conocimientos nuevos y esté en la capacidad de implementarlos en la vida real.

Para Valdés (2000) la evaluación del desempeño docente obedece al cumplimiento de funciones de diagnóstico, instructiva, educativa, desarrolladora de control, así mismo 
señala que las dimensiones de la evaluación del desempeño docente son: dominio tecnológico, dominio científico, responsabilidad en el desempeño de sus funciones, relaciones interpersonales y formación en valores éticos.

Para Cherry (2016) citado por Ludeña (2019) es posible evaluar el desempeño en distintos entornos o contextos: el contexto sociocultural, el entorno institucional, el ambiente del aula y, en algunos casos, uno mismo a través de una acción reflexiva. Por consiguiente, la competencia docente contiene cualidades y destrezas que pueden ser movilizadas para afrontar diversas situaciones que pueden surgir durante las sesiones de clase.

Por otro lado, de acuerdo con lo planteado por Valdés (2000) citado por Fernández (2002), surgen cuatro modelos de evaluación de la eficacia docente:

- Modelo centrado en el perfil del maestro: Reside en la evaluación del desempeño docente de acuerdo con el nivel de correspondencia entre las cualidades y características de un perfil preestablecido. Este perfil se elabora en base a las percepciones que diferentes grupos de personas: alumnos, padres de familia, directivos y profesores, tienen acerca de lo que es ser un buen profesor. Una vez establecido el perfil, se elaboran cuestionarios que se pueden aplicar a manera de autoevaluación, mediante un evaluador externo que entrevista al profesor, mediante la consulta a los alumnos y sus padres, etc.

- Modelo centrado en los resultados obtenidos: Consiste en evaluar el desempeño docente mediante el control de los aprendizajes obtenidos por los estudiantes; como consecuencia de lo que el docente hace, pudiendo descuidar aspectos del proceso enseñanza - aprendizaje, determinantes de la calidad educativa.

- Modelo centrado en el comportamiento del docente en el aula: Consiste en la evaluación docente a través de la identificación de la conducta docente asociada a los logros de los estudiantes; por ejemplo, la aptitud del docente para crear un entorno 
propicio para el aprendizaje, uso de pautas de observación, tablas de interacción o diferentes escalas de medida del comportamiento docente.

- Modelos de la práctica reflexiva: Una evaluación que se compone de una sucesión de pasos para hallar problemas o conflictos invitando al equipo académico a la mejoría de sus procedimientos. En la ejecución de este modelo se consideran tres momentos: el primero correspondiente a la observación y registro anecdótico de la actividad, el segundo relacionado al establecimiento de un diálogo reflexivo con el observador para discutir lo observado, y finalmente un diálogo de seguimiento en la que se reanudan las ideas y acciones establecidas.

En el Perú, en diciembre del 2011, el Consejo Nacional de Educación entregó la propuesta de Marco Orientador del Buen Desempeño Docente al Ministerio de Educación. En marzo del 2012, se constituyó el Grupo Impulsor del Marco del Buen Desempeño Docente con el propósito de convocar a un panel de expertos para revisar la propuesta. En ese mismo año, el MINEDU desarrolló jornadas de reflexión sobre el presente Marco del Buen Desempeño Docente con el propósito de dar a conocer el documento y enriquecerlo en materia de claridad y pertinencia.

Asimismo, MINEDU (2012) sostiene que el Marco de Buen Desempeño Docente “es una guía imprescindible para el diseño e implementación de las políticas y acciones de formación, evaluación y desarrollo docente a nivel nacional” (p.8). Este marco se compone de elementos organizados jerárquicamente en cuatro dominios, los cuales comprenden nueve competencias que a su vez integran cuarenta desempeños.

En cuanto a los antecedentes de investigación internacional de las variables de estudio se tiene a Correa y Patiño (2016) determinaron la relación que existe entre el uso de las TICs y el desempeño docente. La muestra se compuso por 30 docentes del nivel secundaria de la Institución Educativa Jorge Eliecer Gaitán de Tota, Colombia. Se empleó 
el Cuestionario uso de las TICs y desempeño docente creado por Correa y Patiño en 2016, la primera variable se agrupa en tres categorías: Competencias tecnológicas, Competencias Comunicativas y Competencias Investigativas y la segunda variable tiene tres dimensiones: Organización del espacio, Estrategias Metodológicas y Materiales Educativos. Como resultado se obtuvo una relación fuerte entre las variables de estudio, siendo altamente significativo con un valor $\mathrm{p}=.<0.0001$, asimismo cada competencia tuvo un nivel moderado de uso de las TIC con el 70\% las competencias tecnológicas, el $47 \%$ las competencias comunicativas y también el $47 \%$ las competencias investigativas. En conclusión, el uso de las TICs con relación al desempeño docente es fundamental para el desarrollo de la práctica pedagógica en los procesos de enseñanza.

Asimismo, Villén (2020) llevó a cabo un estudio cuyo objetivo fue conocer las creencias del profesorado sobre las tecnologías educativas (TIC) durante el confinamiento por la pandemia del COVID-19 con relación a las actitudes y emociones, la formación y las competencias y la importancia de las TIC. La muestra estuvo conformada por 1000 docentes durante el curso escolar 2019/2020 en España. El 69.9 \% fueron mujeres, el 29.5 $\%$ hombres y el $0.6 \%$ es género binario/otro/prefiero no contestar, entre la edad de 20 y más de 65 años. Se usó el Cuestionario sobre las creencias del profesorado sobre la tecnología que fue creado por Villén (2020). Los resultados evidencian que el $72.4 \%$ obtuvo una actitud positiva, el $24.40 \%$ una actitud neutra, el $84.40 \%$ una actitud proactiva, el $78.50 \%$ una actitud colaboradora e integradora y un $10.60 \%$ permisiva. Asimismo, se evidencia que los docentes jóvenes presentaron actitudes más positivas, reactivas, interesadas, asertivas y emocionales frente a los docentes de mayor edad. En conclusión, los docentes han experimentado emociones principalmente de calma, sorpresa y alegría, una necesidad de formación y disposición en competencia digital alta 
y un incremento considerable de la importancia de las TIC durante y después de la pandemia.

Del mismo modo, Sandoval (2020) llevó a cabo una investigación, que tuvo por objetivo realizar un análisis crítico sobre la actitud o postura de los docentes del uso y adaptación de las tecnologías, que se ha visto afectado por el Coronavirus. La muestra estuvo conformada por 5 directivos, 25 docentes y 99 padres de familia pertenecientes al nivel educativo básico - primario de los colegios de Sandra Catalina y Jardín infantil San Arcángel en la ciudad de Bogotá. El instrumento empleado fue la Encuesta para identificar el impacto del COVID-19 en el proceso pedagógico, también incluyó el uso de las TIC en el proceso educativo, desarrollado por Sandoval (2020). Los resultados mostraron que el $80.8 \%$ de los docentes ha tenido un alto impacto por causa de la pandemia del COVID-19, además el 34.6\% considera que el proceso de enseñanza de las clases con los estudiantes se ha visto afectado y el $84.6 \%$ de los docentes considera que ha sido difícil adaptarse en los procesos de enseñanza-aprendizaje. Concluyeron que el COVID -19 ha provocado una disrupción en el sistema educativo, por lo que se debe implementar la modalidad virtual como valor agregado a la propuesta educativa al crecimiento profesional docente.

Hidalgo (2020) quien investigó las competencias profesionales docentes de Educación Básica Regular a partir del Marco del Buen Desempeño Docente. La muestra estuvo compuesta por 29 docentes de la especialidad de educación inicial y primaria, con edades entre 21 y 25 años, egresados en el 2017 y que trabajan en instituciones de educación básica. Como instrumento usó una ficha de evaluación de competencias profesionales docentes (Hidalgo, 2020) teniendo en cuenta el Marco de Buen Desempeño Docente del 2012 que contiene 4 dominios: preparación para el aprendizaje de los estudiantes; enseñanza para el aprendizaje de los estudiantes, participación en la gestión 
de la escuela articulada a la comunidad y desarrollo de la profesionalidad y la identidad docente; además de 9 competencias y cuarenta desempeños profesionales. Los resultados muestran respecto al dominio de preparación para el aprendizaje de los estudiantes, un nivel notable de logro (42\%); respecto a la enseñanza para el aprendizaje de los estudiantes se obtuvo un nivel notable de logro (23.1\%); en participación en la gestión de la escuela articulada a la comunidad, se obtuvo un nivel de insuficiencia (63.1\%) y en el desarrollo de la profesionalidad y la identidad docente se obtuvo un nivel de logro suficiente $(94.5 \%)$. Se concluyó, un nivel de logro suficiente teniendo en cuenta el periodo de pandemia por Covid-19 que exige el uso de plataformas virtuales como medio de aprendizaje, en el que deben perfeccionar su ejercicio profesional a través de cursos de formación continua.

Baptista, Loeza, Almazán, López y Cárdenas (2020) realizaron un estudio con el fin de describir actividades de docentes mexicanos llevan a cabo para dar continuidad al año académico. La muestra estuvo conformada por 2253 docentes de educación básica pública de la República de México de diversos niveles educativos (preescolar, primaria, secundaria y bachillerato) quienes ya habían tenido contacto con las TIC en sus centros educativos, con edades entre 22 y 73 años, el $18 \%$ son hombres y $82 \%$ mujeres, el $7 \%$ trabaja en zonas rurales y el $63 \%$ en zonas urbanas. Se usó el cuestionario de autoreporte END-COVID-19 para docentes, diseñada por Baptista, et. al. (2020) que consta de 19 preguntas (17 cerradas y 2 abiertas). El área de indagación Actividades conducentes a la continuidad de las clases durante la emergencia Covid 19, cuenta con tres componentes: actividades de gestión, actividades de enseñanza y actividades para aprender. Los resultados muestran diferencias significativas entre región geográfico-educativa y medios de comunicación de los docentes con padres de familia, baja-media de acuerdo con el Coeficiente V de Cramer (0.11), región geográfico-educativa y uso de herramientas 
digitales como medio de aprendizaje a distancia que utilizan los docentes, baja-media de acuerdo con el Coeficiente V de Cramer (0.10), nivel educativo y el uso de herramientas digitales como medio de aprendizaje a distancia que utilizan los docentes, baja-media, de acuerdo con el Coeficiente V de Cramer (0.14). Los autores concluyen que los docentes promueven el uso de herramientas digitales, acciones relacionadas con sus capacidades de gestión, enseñanza-aprendizaje, sin embargo, no todos los docentes poseen esas capacidades para proporcionar aprendizaje digital de manera individualizada, siendo en algunos casos indispensable el uso de otros recursos tradicionales.

Por otro lado, en Perú, Vargas (2019) evaluó la relación entre el uso de las TIC y el desempeño docente en la I.E. $N^{\circ} 1228$ Leoncio Prado Gutiérrez - Ate. Con una muestra de 58 docentes. Se usó la Escala para medir las TICs de Vargas (2019) conformada por tres dimensiones: recursos tecnológicos, actitud hacia las TIC y didáctica del uso de las Tic. Igualmente, la Escala para medir el desempeño docente de Vargas (2019) tiene tres dimensiones: eje mediador en el aprendizaje, actitud crítica y actitud creativa. Los resultados mostraron que existe un grado de relación moderada de .715 , con una significancia de .004. entre las TIC y el desempeño docente. Además, se evidencia una correlación positiva moderada entre los recursos tecnológicos y el desempeño de.706; entre actitud hacia las TIC y desempeño docente una correlación de .611. Y la relación entre la didáctica del uso de las TIC y el desempeño docente de .764 con una significancia de .008. Por lo que se concluye que si existe relación entre las TIC y el desempeño docente.

Asimismo, Oyarce (2016) realizó una investigación con el propósito de establecer una asociación entre el uso de las TIC y el desempeño docente. La muestra estuvo constituida por 20 docentes de la escuela de comunicación social de la Universidad Nacional Mayor de San Marcos y 100 estudiantes entre primer y quinto año de estudios. 
Se usó el Cuestionario de Uso de TIC agrupada en tres dimensiones: gestores de documentos, gestores de aprendizaje y gestores de contenido y el Cuestionario de desempeño docente con calidad agrupado en tres dimensiones: estrategias docentes, materiales didácticos y capacidades pedagógicas; ambos cuestionarios fueron creados por Oyarce en 2016 y sometidos a juicio de experto con una validez de $61.80 \%$ muy bueno y una confiabilidad excelente de .932. Los resultados evidencian una relación altamente significativa entre el adecuado uso de las TICs y el desempeño docente con calidad de los docentes $(.787 ; p<.000)$ asimismo entre uso adecuado de las TICs y el desempeño docente de calidad de los estudiantes (.664; $p<.000)$. Se concluyó que el dominio de los docentes sobre las TIC mejora su desempeño fortaleciendo sus capacidades pedagógicas y estratégicas, además de afianzar la relación con los alumnos.

De la misma forma, Chero (2020) realizó un estudio con el objetivo de determinar la relación entre la utilización de las TICs y el desempeño docente de una universidad peruana. La muestra estuvo compuesta por 100 docentes, el $44 \%$ fueron mujeres y el $56 \%$ fueron varones; el 29\% estaba entre los 50 años a más de edad, el 37\% tuvieron entre 3 a 6 años de servicio. Se usó el cuestionario de utilización de las TICs creado por Chero (2020), cuenta con tres dimensiones: herramientas para el proceso de información, fuente de información y recursos y Canales de Información; además del cuestionario de desempeño docente creado por Chero (2020), cuenta con dimensiones: socialización, manejo del tiempo, incentiva a la creatividad y pensamiento crítico, evalúa el progreso de los aprendizajes y motiva un ambiente de respeto y cooperación. Los resultados evidencian un alto nivel de significancia entre la utilización de las Tics y desempeño docente $(r=.575 ; p<.000)$ y sus dimensiones. Se concluye que la percepción sobre la utilización de las TICs juega un papel importante en el desempeño docente. 
De forma similar, Olivera (2015) realizó una investigación con el propósito de relacionar el uso de recursos informáticos y desempeño docente. La muestra estuvo conformada por 128 docentes de la facultad de ingeniería de la Universidad Peruana Los Andes - Filial Lima 2015. Se usó el cuestionario de uso de recursos informáticos creado por Olivera en 2015, el cual se conforma de cinco dimensiones: uso intensivo de internet, proyector multimedia, correo electrónico, foros de debate y plataforma virtual. Además del Cuestionario de desempeño docente creado por Olivera en 2015, conformado por cuatro dimensiones: capacidades pedagógicas, competencias docentes, satisfacción laboral y actitud del docente. Los resultados muestran que existe una relación positiva y débil ( $r=.393)$ entre el uso de los recursos informáticos y el desempeño docente de la Facultad de Ingeniería de la Universidad Peruana Los Andes Filial - Lima.

\section{Justificación}

El presente estudio se justifica a nivel teórico, debido a que busca generar reflexión y una nueva mirada hacia las actitudes hacia el uso de las TICs y el desempeño docente en competencias duras y blandas haciéndolos capaces de relacionarse y comunicarse de manera efectiva con sus estudiantes a través de la educación virtual durante el periodo de confinamiento por la pandemia.

Por otra parte, esta investigación se justifica a nivel práctico ya que permitirá plantear estrategias para favorecer un mejor desempeño docente y mejorar las competencias informáticas a través de la ampliación de la visión del problema y la mejora de actitudes de enseñanza con estas tecnologías buscando una adaptación positiva hacia el uso de las TIC.

Finalmente, basado en los estudios señalados anteriormente este se justifica a nivel metodológico, dado que busca generar conocimiento sobre el fenómeno en mención, desde una postura cuantitativa, utilizando herramientas válidas de forma virtual y remota 
que permiten profundizar el estado del arte de las actitudes hacia el uso de las TIC y el desempeño autopercibido en docentes de Lima. Aunado a ello, el evaluar a los docentes en contexto de pandemia, permitirá promover otras investigaciones sobre fenómenos similares.

\section{Objetivos}

El objetivo general de esta investigación fue relacionar la actitud hacia el uso de las TICs y el desempeño autopercibido en docentes de Lima en confinamiento por COVID19. Con respecto a los objetivos específicos, estos se propusieron en base a la asociación entre las dimensiones de la actitud hacia las TICs y las dimensiones del desempeño autopercibido, siendo estas las siguientes:

- Determinar los niveles de actitud hacia el uso de las TICs en docentes de Lima en confinamiento por COVID-19.

- Determinar la percepción de desempeño en docentes de Lima en confinamiento por COVID-19.

- Determinar la relación entre actitud hacia las TICs y evaluación de desempeño en el aula, autoevaluación de las labores escolares e interacción con los estudiantes.

- Determinar la relación entre desempeño autopercibido y actitud cognitiva, actitud afectiva y actitud conductual.

- Determinar la relación entre actitud cognitiva y evaluación de desempeño en el aula, autoevaluación de las labores escolares e interacción con los estudiantes.

- Determinar la relación entre actitud afectiva y evaluación de desempeño en el aula, autoevaluación de las labores escolares e interacción con los estudiantes.

- Determinar la relación entre actitud conductual y evaluación de desempeño en el aula, autoevaluación de las labores escolares e interacción con los estudiantes. 


\section{Hipótesis}

En relación con la hipótesis general, se estableció que, existe una relación positiva entre la actitud hacia el uso de las TICs y el desempeño autopercibido en docentes de Lima en confinamiento por COVID-19. Así mismo, se determinaron las siguientes hipótesis específicas:

$\mathrm{h}_{1}$ : Existe una relación positiva entre actitud hacia las TICs y evaluación de desempeño en el aula, autoevaluación de las labores escolares e interacción con los estudiantes. $\mathrm{h}_{2}$ : Existe una relación positiva entre desempeño autopercibido, actitud cognitiva, actitud afectiva y actitud conductual.

$\mathrm{h}_{3}$ : Existe una relación positiva entre actitud cognitiva y evaluación de desempeño en el aula, autoevaluación de las labores escolares e interacción con los estudiantes.

h4: Existe una relación positiva entre actitud afectiva y evaluación de desempeño en el aula, autoevaluación de las labores escolares e interacción con los estudiantes.

$\mathrm{h}_{5}$ : Existe una relación positiva entre actitud conductual y evaluación de desempeño en el aula, autoevaluación de las labores escolares e interacción con los estudiantes. 


\section{Método}

\section{Tipo y diseño de investigación}

La investigación es de tipo no experimental, con estrategia asociativa y de estudio transversal ya que se recogerán los datos en un solo punto del tiempo con un enfoque cuantitativo, debido a que se relacionan las variables actitud hacia el uso de las TICs y desempeño autopercibido, ambas guardan el mismo estatus metodológico (Ato, López \& Benavente, 2013).

\section{Participantes}

El muestreo fue no probabilístico por conveniencia y con consentimiento informado (Otzen \& Manterola, 2017). Los criterios de inclusión que se consideraron son los siguientes: docentes que realicen trabajo remoto en Lima Metropolitana y pertenezcan a la gestión de educación pública. Esto, debido al acceso por el tipo de muestreo seleccionado y se consideró que la mayoría de los docentes de gestión pública con la estrategia utilizada "Aprendo en casa" presenta mayores dificultades y limitaciones en cuanto a recursos, capacitación y uso de las tecnologías de la información (Diario Perú 21, 2020). Por lo que del total de 103 docentes encuestados se eliminaron 17 docentes por realizar trabajo remoto fuera de Lima Metropolitana y 17 docentes que pertenecían a la gestión educativa privada.

Participaron de la investigación 69 docentes de Educación Básica Regular de los niveles inicial, primaria y secundaria de diversas instituciones educativas de Lima Metropolitana. De edades comprendidas entre 24 y 63 años $(M=45.3, D E=9.44), 54$ de los docentes fueron mujeres (78.3\%) y 15 hombres $(21.7 \%)$. La mayoría de los docentes trabaja en el nivel educativo primaria (63.8\%) y de manera remota más de 8 meses (71\%).

La mayoría de los docentes manifestaron hacer uso de herramientas digitales como Google Meet y WhatsApp (24.4\%), tener acceso a dos dispositivos electrónicos (65.2\%) para uso profesional: como celular y laptop (31.9\%) para el desarrollo de sus clases de 
manera remota, además de compartir estos con 2 personas más dentro de su hogar $(37.7 \%)$

\section{Instrumentos de recolección de medición}

Para el presente estudio se utilizó la Escala de actitud: uso de Tecnologías de Información y Comunicación (TIC) en la enseñanza construida por Granda (2018) para el contexto peruano. El cuestionario consta de 30 ítems (21 ítems de dirección positiva y 9 tienen valores inversos) con respuesta de tipo Likert con cinco opciones de respuesta: rechazo total (1); rechazo (2); indiferente (3); aceptación (4) y aceptación total (5). Los ítems se encuentran agrupados en tres componentes actitudinales: cognitivo $(1,2,6,9$, $11,13,20,26,27,28)$, afectivo $(3,5,8,10,14,17,22,25,29,30)$ y conductual $(4,7,12$, $15,16,18,19,21,23,24)$. El coeficiente de reproductividad fue de .90 , indicando que el número de errores es aceptable. Cuenta con un valor alfa de Cronbach de .89 que indica a la prueba como estable, segura y confiable (Granda, 2018).

El instrumento usado para medir la variable Desempeño docente, es el Autorreporte del desempeño docente elaborado por Fernández (2002) para el contexto peruano. El cuestionario utiliza una escala de tipo Likert de siete puntos nunca (1), casi nunca (2), a veces (3), en duda (4), ocasionalmente (5), casi siempre (6) y siempre (7), constituida por 47 ítems que están agrupados en los siguientes dimensiones: evaluación del desempeño en el aula $(3,5,7,8,9,10,11,12,16,18,21,23,26,27,31,32,37,39,41,42,43,44$, 45 y 46), autoevaluación de las labores en el ámbito escolar (14, 15, 17, 19, 20, 22, 24, $28,29,30,33,34,35,38,40$ y 47) e interacción con los alumnos (1, 2, 4, 6, 13, 25 y 36). Se hallaron evidencias de validez de contenido a través de la consulta a 9 jueces expertos, $\mathrm{p}<0.5$ y se obtuvo un alfa de Cronbach $=0.91$ denotando un nivel alto de confiabilidad para toda la prueba (Fernández, 2002). 
Para el presente estudio, el análisis de confiabilidad en la Escala de Actitud hacia el uso de las TICs respecto a su consistencia interna, esta se estudió través del alpha de Cronbach obteniéndose un coeficiente $\alpha=.65$ (aceptable) para la dimensión: actitud cognitiva; un coeficiente $\alpha=.69$ (aceptable) para la dimensión: actitud afectiva, la cual originalmente se componía de 10 ítems, luego de una discusión se llegó a la conclusión de retirar 4 ítems $(8,17,25$ y 30$)$ ya que al mantenerlos se indicaba un alfa por debajo del mínimo aceptable; un coeficiente $\alpha=.78$ (buena) para la dimensión: actitud conductual, la que originalmente se componía de 10 ítems, luego de una discusión, se llegó a la conclusión de retirar 3 ítems $(4,12$ y 18) ya que al mantenerlos se indicaba un alfa por debajo del mínimo aceptable.

Respecto al Autoreporte de desempeño docente, para el primer factor evaluación de desempeño, la consistencia interna a través del Alpha de Cronbach arrojó un $\alpha=.91$ (excelente). El segundo factor autoevaluación de las labores escolares muestra un $\alpha=.71$ (aceptable) y el tercer factor interacción con los estudiantes un $\alpha=.73$ (buena), este originalmente se componía de 7 ítems, luego de una discusión, se llegó a la conclusión de retirar 2 ítems (13 y 25) ya que al mantenerlos se indicaba un alfa por debajo del mínimo aceptable.

\section{Procedimientos}

En primer lugar, se solicitó a los autores, los permisos correspondientes para el uso de los instrumentos de evaluación a través del correo electrónico; luego se adaptó, el consentimiento informado, la ficha sociodemográfica y los instrumentos a un formato virtual gratuito (Google Forms), para llevar a cabo el proceso de administración de forma remota, asincrónica y a conveniencia del participante, la ejecución del cuestionario estaba determinado a realizarse por un tiempo aproximado de 15 minutos. 
Cabe mencionar, que la elección de este medio se eligió por acceso a la muestra con el fin de respetar el contexto de emergencia sanitaria, periodo en el cual se realizó la investigación, durante cuatro semanas.

La recolección de datos se inició con la administración del consentimiento informado que iniciaba con una breve presentación de las bachilleres y su casa de estudios, seguidamente se explicaba el objetivo del estudio y se invitó al docente a ser partícipe de este de manera voluntaria y anónima, señalando que sus datos serán manejados con estricta confidencialidad (ver anexo 1), con base al código de ética del colegio de psicólogos del Perú (2018). En segundo lugar, se mostraba la ficha sociodemográfica (ver anexo 2), la cual abarcó los criterios de inclusión y exclusión. En tercer lugar, se muestra la Escala de Actitud hacia el uso de TICs en la enseñanza (ver anexo 3) y el Autorreporte de desempeño docente (ver anexo 4) con sus respectivas instrucciones. Finalmente, se confirmó el registro de las respuestas a cada cuestionario y se agradeció la participación de los docentes, así mismo se informó que si el participante deseara conocer los resultados del estudio podría contactarse al siguiente correo: karina.choquecota@usil.pe

Una vez obtenido los datos necesarios, se inició el proceso de eliminación de datos en base a los criterios de exclusión antes mencionados.

\section{Análisis de datos}

El tratamiento de los datos se llevó a cabo a través de software Jamovi versión 1.2. El análisis de confiabilidad se realizó por medio del puntaje del coeficiente de $\alpha$, tomando en cuenta el tamaño de la muestra menor a 100 (69 docentes) y el número de ítems de cada dimensión, menor a 6 ítems el valor mínimo aceptable es .60, entre 7 y 11 ítems, el valor mínimo aceptable es .65 y desde 12 a más ítems el valor mínimo aceptable es .70 (Ponterotto \& Ruckdeschel, 2007). Luego se analizaron los estadísticos descriptivos y los 
supuestos de normalidad de asimetría y curtosis (valor mínimo aceptable 3). Respecto al análisis de la correlación entre las variables Actitud al uso de las TICs y desempeño docente, así como sus respectivas dimensiones estas se interpretaron teniendo en cuenta los siguientes puntos de corte: $.20=$ insignificante, entre .20 y $.50=$ baja; entre .50 y .80 $=$ moderada y mayor que $.80=$ fuerte (Domínguez-Lara, 2017). 


\section{Resultados}

A continuación, se presentan los hallazgos obtenidos mediante los procesos de análisis de acuerdo con los objetivos e hipótesis planteadas para esta investigación en torno a las variables y dimensiones de estas, además de los resultados descriptivos y de normalidad.

\section{Análisis descriptivo}

En la tabla 1 se muestran los promedios y desviación estándar de las puntuaciones generales y las dimensiones de cada variable. Se realizaron las pruebas de normalidad de simetría y curtosis de las variables de estudio con el fin de valorar la pertinencia de las pruebas paramétricas y no paramétricas. Para el análisis de la normalidad de los datos se tomaron en cuenta las dimensiones de cada instrumento; los resultados obtenidos muestran (ver tabla $1, g_{2}$ ) que las dimensiones cumplen con el criterio de normalidad a través de la curtosis (ser menores de tres), por lo que no se presentan dificultades para usar una prueba paramétrica (Pearson), debido a que se presentan niveles adecuados de normalidad a excepción de la dimensión evaluación de desempeño en el aula. 
Tabla 1.

Análisis descriptivos de las variables de estudio

\begin{tabular}{lccccc}
\hline Variables y dimensiones & $\mathrm{n}$ & $\mathrm{M}$ & $\mathrm{DE}$ & $\mathrm{g}_{1}$ & $\mathrm{~g}_{2}$ \\
\hline Actitud hacia el uso de las TICs & 69 & 96.2 & 9.81 & -0.91 & 0.003 \\
Actitud Cognitiva & 69 & 39.6 & 4.35 & -0.79 & -0.27 \\
Actitud Afectiva & 69 & 25.4 & 3.32 & -0.45 & -0.90 \\
Actitud Conductual & 69 & 31.2 & 3.31 & -1.04 & 0.53 \\
Desempeño autopercibido & 69 & 228 & 19.9 & -1.34 & 4.94 \\
Evaluación de desempeño en el aula & 69 & 149 & 16.6 & -2.27 & 6.81 \\
Autoevaluación de las labores en el ámbito escolar & 69 & 51.6 & 10.8 & 0.52 & -0.72 \\
Interacción con los alumnos & 69 & 27.8 & 4.73 & -1.11 & 1.14 \\
\hline
\end{tabular}

Nota: $n=$ tamaño muestral; $M=$ Media $; D E=$ desviación estándar; $g_{1}=$ asimetría $; g_{2}=$ curtosis

Los niveles en los que se encuentran los docentes de Lima Metropolitana respecto a la actitud hacia el uso de las TICs y la percepción de su desempeño durante las sesiones remotas en los últimos meses muestran los siguientes resultados (ver tabla 2).

Tabla 2.

Niveles de actitud hacia el uso de las Tics en docentes de Lima Metropolitana

\begin{tabular}{ccc}
\hline \multirow{2}{*}{ Niveles } & \multicolumn{2}{c}{ Actitud hacia el uso de las Tics } \\
\cline { 2 - 3 } & $\mathrm{N}$ & $\%$ \\
\hline Medio & 39 & $56.5 \%$ \\
Alto & 30 & $43.5 \%$ \\
Total & 69 & $100 \%$ \\
\hline
\end{tabular}

Nota: Baremo para población peruana (Granda, 2018) 
Por otro lado, en la tabla 3 se observa los resultados del desempeño autopercibido en docentes de Lima Metropolitana.

Tabla 3.

Desempeño autopercibido en docentes de Lima Metropolitana

\begin{tabular}{ccc}
\hline & \multicolumn{2}{c}{ Desempeño Autopercibido } \\
\cline { 2 - 3 } Percentiles & $\mathrm{N}$ & $\%$ \\
\hline 1 & 23 & $33.3 \%$ \\
5 & 29 & $42 \%$ \\
10 & 8 & $11.6 \%$ \\
15 & 3 & $4.3 \%$ \\
20 & 1 & $1.4 \%$ \\
40 & 2 & $2.9 \%$ \\
Total & 3 & $4.3 \%$ \\
\hline
\end{tabular}

Nota: Baremo para Lima Metropolitana (Fernández, 2002).

\section{Contraste de hipótesis}

En cuanto a la hipótesis general, se encontró una relación positiva entre actitud hacia el uso de las TICs y el desempeño autopercibido en docentes de Lima Metropolitana durante el confinamiento por COVID-19, $(\mathrm{r}=.47 ; \mathrm{p}<.05)$, aunque de baja magnitud, lo que brinda respaldo empírico a la hipótesis de investigación.

Respecto a la hipótesis específica 1, de acuerdo con los resultados obtenidos, se rescata la existencia de una asociación positiva y estadísticamente significativa entre actitud hacia las TICs y evaluación de desempeño en el aula $(r=.70 ; p<.05)$ de moderada magnitud, lo que brinda un respaldo empírico a la hipótesis de investigación. Existe una asociación negativa y estadísticamente significativa entre actitud hacia las TICs y autoevaluación de las labores escolares $(r=-.42 ; \mathrm{p}<.05)$ con baja magnitud, lo que no 
brinda un respaldo empírico a la hipótesis de investigación y finalmente, existe una asociación positiva y estadísticamente significativa entre la actitud hacia las TICs y la interacción con los estudiantes $(r=.51 ; \mathrm{p}<.05)$ esto con moderada magnitud, lo que brinda un respaldo empírico a la hipótesis de investigación.

De acuerdo con los resultados, para la hipótesis específica 2, existe una relación positiva y estadísticamente significativa entre desempeño autopercibido y actitud cognitiva $(\mathrm{r}=.43 ; \mathrm{p}<.05)$, aunque de baja magnitud. Asimismo, existe una asociación positiva y estadísticamente significativa entre desempeño autopercibido y actitud afectiva $(\mathrm{r}=.41 ; \mathrm{p}<.05)$, aunque de baja magnitud y finalmente existe una asociación positiva y estadísticamente significativa entre desempeño autopercibido y actitud conductual $(\mathrm{r}=$ $.43 ; \mathrm{p}<.05)$, aunque de baja magnitud, lo que brinda un respaldo empírico a la hipótesis de investigación.

Respecto a los resultados de la hipótesis específica 3, existe una relación positiva y estadísticamente significativa entre actitud cognitiva y evaluación de desempeño en el aula $(\mathrm{r}=.65 ; \mathrm{p}<.05)$ de moderada magnitud, lo que brinda respaldo empírico a la hipótesis de investigación; Por otra parte, existe una asociación negativa y estadísticamente significativa entre actitud cognitiva y autoevaluación de las labores escolares $(\mathrm{r}=-.39 ; \mathrm{p}<.05)$, aunque de baja magnitud, lo que no brinda respaldo empírico a la hipótesis de investigación y finalmente, existe una asociación positiva y estadísticamente significativa entre actitud cognitiva e interacción con los estudiantes (r $=.44 ; \mathrm{p}<.05)$ pero con baja magnitud, lo que brinda respaldo empírico a la hipótesis de investigación.

De acuerdo con los resultados, para la hipótesis específica 4, existe una relación positiva y estadísticamente significativa entre actitud afectiva y evaluación de desempeño en el aula $(r=.60 ; \mathrm{p}<.05)$ de moderada magnitud, lo que brinda respaldo empírico a la 
hipótesis de investigación; A su vez, existe una asociación negativa y estadísticamente significativa entre la actitud afectiva y la autoevaluación de las labores escolares $(r=-.40$; $\mathrm{p}<.05)$, aunque esto con baja magnitud, lo que no brinda respaldo empírico a la hipótesis de investigación y finalmente, existe una asociación positiva y estadísticamente significativa entre la actitud afectiva e la interacción con los estudiantes $(r=.51 ; p<.05)$ con moderada magnitud, lo que brinda respaldo empírico a la hipótesis de investigación.

Y para la hipótesis específica 5, de acuerdo con los resultados, existe una asociación positiva y estadísticamente significativa entre actitud conductual y evaluación de desempeño en el aula $(r=.61 ; p<.05)$ con moderada magnitud, lo que brinda respaldo empírico a la hipótesis de investigación. Asimismo, existe una asociación negativa y estadísticamente significativa entre actitud conductual y autoevaluación de las labores escolares $(r=-.34 ; p<.05)$ con baja magnitud, lo que no brinda respaldo empírico a la hipótesis de investigación y finalmente, existe una asociación positiva y estadísticamente significativa entre actitud conductual e interacción con los estudiantes $(r=.42 ; \mathrm{p}<.05)$ con baja magnitud, lo que brinda respaldo empírico a la hipótesis de investigación.

Tabla 4.

Desempeño autopercibido en docentes de Lima Metropolitana

\begin{tabular}{|c|c|c|c|c|c|c|c|c|}
\hline \multirow[t]{2}{*}{$\begin{array}{c}\text { Variables y } \\
\text { dimensiones }\end{array}$} & \multicolumn{2}{|c|}{$\begin{array}{l}\text { Desempeño } \\
\text { Autopercibido }\end{array}$} & \multicolumn{2}{|c|}{$\begin{array}{c}\text { Evaluación de } \\
\text { desempeño en el } \\
\text { aula }\end{array}$} & \multicolumn{2}{|c|}{$\begin{array}{c}\text { Auto-evaluación de } \\
\text { las labores } \\
\text { escolares }\end{array}$} & \multicolumn{2}{|c|}{$\begin{array}{l}\text { Interacción con los } \\
\text { estudiantes }\end{array}$} \\
\hline & $r$ & $p$ & r & $p$ & $r$ & $p$ & r & $p$ \\
\hline $\begin{array}{l}\text { Actitud hacia el } \\
\text { uso de las TICs }\end{array}$ & 473 & .001 & .697 & .001 & -.423 & .001 & .511 & .001 \\
\hline $\begin{array}{l}\text { Actitud } \\
\text { Cognitiva }\end{array}$ & .434 & .001 & .651 & .001 & -.393 & .001 & .439 & .001 \\
\hline Actitud Afectiva & .406 & .001 & .599 & .001 & -.397 & .001 & .513 & .001 \\
\hline $\begin{array}{c}\text { Actitud } \\
\text { Conductual }\end{array}$ & .426 & .001 & .610 & .001 & -.338 & .005 & .424 & .001 \\
\hline
\end{tabular}

Nota: $p<.01$ 
La hipótesis de investigación muestra un asociación positiva respecto a las variables de estudio, así como las dimensiones de la variable actitud hacia el uso de las tics muestran una asociación positiva, significativa, de baja a moderada magnitud a nivel práctico con las dimensiones del desempeño autopercibido, a excepción de la dimensión autoevaluación de las labores escolares que muestra una asociación negativa respecto a las tres dimensiones de la actitud y al puntaje total de actitud hacia el uso de las TICs. 


\section{Discusión}

En el Perú, se establecieron medidas preventivas necesarias para evitar la propagación de la pandemia por COVID-19. El aislamiento social obligatorio forzó al sector educativo, especialmente a los docentes, adaptarse a una nueva modalidad de trabajo remoto a través del uso de las TICs para la enseñanza y el desempeño de sus funciones, llevando a cabo los procesos de enseñanza y aprendizaje dentro de las aulas virtuales, evitando así la pérdida del año escolar.

Por lo tanto, la presente investigación tuvo como objetivo de estudio relacionar la actitud hacia el uso de la TICs y desempeño autopercibido en docentes de Lima en confinamiento por COVID-19, así mismo se relacionan las actitudes cognitivas, afectivas y conductuales con la evaluación de desempeño en el aula, la auto-evaluación de las labores escolares y la interacción con los estudiantes.

En cuanto al objetivo orientado a la determinación del nivel de la actitud hacia el uso de las TICs en docentes, se obtuvo un nivel medio-alto en los docentes. Esto puede deberse a que la mayoría de los docentes tuvo una formación previa (capacitación) al uso de las TICs, por lo que desarrollaron y potenciaron habilidades y actitudes favorables en cuanto al uso de las TICs como recursos académicos para diversas asignaturas (Tapia, 2018).

Resultados similares se obtuvieron en Borda y Flores (2018) quienes mostraron una actitud favorable por parte de los docentes hacia el uso de las TICs y Vargas (2019) mostraron una actitud regular del uso de las TICs, difieren en Mendoza y Lukis (2020) quienes hallaron una baja actitud en docentes en el uso de las TICs, así como en el estudio de Ingaruca (2020) en el que los docentes obtuvieron niveles medios-bajos en el uso de las TICs y en Padilla (2018) donde los docentes mostraron una actitud negativa al uso de las TICs. 
En cuanto al objetivo orientado a percepción del desempeño en docentes, se obtuvo una baja autopercepción de su desempeño, debido a que este constructo implica desenvolvimiento individual en el aula, interacción con la comunidad educativa (directivos, estudiantes y familias), rendimiento de sus estudiantes y su relación con la vida del colegio (labores extracurriculares) Fernández (2002) y al desarrollar sus funciones desde casa durante el periodo de confinamiento algunas interacciones han sufrido cambios en su desarrollo.

Estos resultados difieren de los hallados en Vargas (2019) quienes obtuvieron un buen desempeño docente, Chero (2020) halló un nivel regular de desempeño en docentes, Fernández (2002) obtuvo un predominio del nivel medio y Olivera (2015) manifiesta que los docentes se encuentran satisfechos con su desempeño, además de ello el contexto en el que están realizadas estas investigaciones son distintas al contexto de confinamiento en el que se encontraba la población del presente estudio.

La hipótesis general orientada a la asociación positiva entre actitud hacia el uso de las TICs y desempeño autopercibido, recibió respaldo. Una posible explicación de estos resultados podría ser que las TICs como recurso educativo, incorporan herramientas que propician la obtención de resultados favorables en cuanto al desempeño profesional docente, facilitando la obtención de contenidos digitales actualizados, optimizando el desarrollo de sus actividades, así como de las formas de interacción con los diversos miembros de la comunidad educativa (Rojas \& Ávila, 2019).

Resultados similares se aprecian en Chero (2020), quien halló una asociación positiva, entre la utilización de las TICs y el desempeño docente, así mismo Vargas (2019) obtuvieron una asociación positiva entre actitud hacia las TIC y desempeño docente, Espichán (2017) halló una asociación positiva entre el uso de las TICs con el desempeño del docente. Por su parte, Correa y Patiño (2016) encontraron que el uso de 
TICs y el desempeño docente se asocian positivamente y Olivera (2015) obtuvo una relación positiva pero débil entre el uso de los recursos informáticos y el desempeño docente.

En cuanto a la hipótesis específica orientada a la asociación positiva entre la actitud hacia el uso las TICs y la evaluación del desempeño en el aula e interacción con los estudiantes, recibió respaldo, debido a que este las TICs han sido un medio de mejora de enseñanza en cuanto a la planificación de sesiones virtuales, además que este medio facilita la comunicación entre docente y estudiante (Vargas, 2019) siendo una gran ventaja durante la emergencia sanitaria en tiempo de pandemia. La asociación positiva entre actitud hacia el uso de las TICs y auto-evaluación de las labores escolares no recibió respaldo. Esto puede deberse a que los ítems de esta dimensión estaban relacionados a la percepción que tiene el docente con relación a su vida en el colegio como la interacción en actividades festivas, eventos centrales y reuniones, es decir, toda la actividad dentro del contexto físico laboral (Fernández, 2002) al no desarrollarse debido a la pandemia existe una relación negativa.

Resultados similares hallaron Vargas (2019), en el que establecieron una relación buena entre el uso de TICs y el proceso de enseñanza, en el que reconocían los beneficios de las TICs en la planificación de tareas; además Magdaleno y Llopis (2014), hallaron una asociación positiva entre actitud hacia el uso de las TICS y comunicación con los estudiantes y sus familias.

La hipótesis específica orientada a la asociación positiva entre desempeño autopercibido y actitud cognitiva, actitud afectiva y actitud conductual, recibió respaldo. Esto a causa de que el desempeño de los docentes ha integrado el uso de recursos tecnológicos siendo este un entorno que durante los últimos años y más aún en contexto de pandemia demanda de una buena disposición hacia el uso de las TICs en el proceso 
educativo (Granda, 2018).

Los hallazgos son similares en Chero (2020) halló una asociación positiva y moderada en cuanto a desempeño docente y empleabilidad de los recursos informáticos relacionada a la actitud conductual.

La hipótesis específica orientada a la asociación positiva entre actitud cognitiva y evaluación de desempeño en el aula e interacción con los estudiantes recibió respaldo, mientras que la asociación positiva entre actitud hacia el uso de las TICs y autoevaluación de las labores escolares no recibió respaldo. Puesto que la actitud cognitiva está relacionada al conocimiento y habilidad en relación a la utilidad de las tics en su vida profesional (Granda, 2018), en torno a este contexto, los docentes consideran el uso de las TICs como un medio útil para el desarrollo de su práctica docente durante el año escolar Chero (2020), así como el conocimiento de diversos canales de información y comunicación (mensajería) a través de redes sociales quienes permite una comunicación efectiva e interacción con los estudiantes (Padrón, 2008; Paredes, 2008). En cuanto a la relación negativa obtenida entre la actitud cognitiva y auto-evaluación de las labores escolares se fundamenta en que el uso de las TICs no se han de utilidad para el desempeño de labores escolares extracurriculares como las reuniones, coordinaciones de eventos o festividades educativas, ya que por pandemia fueron suspendidos los eventos de aglomeración masiva en los diversos centros educativos; por ello el conocimiento en cuanto a la utilización de las TICs no han sido consideradas como beneficiosas en esta dimensión (Mejía, Silva, Villarreal, Suarez \& Villamizar, 2018).

La hipótesis específica orientada a la asociación positiva entre actitud afectiva y evaluación de desempeño en el aula e interacción con los estudiantes recibió respaldo, mientras que la asociación positiva entre actitud hacia el uso de las TICs y autoevaluación de las labores escolares no recibió respaldo. Debido a que la actitud afectiva 
está relacionada a la percepción sobre la seguridad, gusto, motivación, así como también los sentimientos de frustración que genera el uso de las TICs (Granda, 2018), por lo que se muestra una relación positiva en cuanto al desempeño de las sesiones escolares de manera remota, pues en un principio de la etapa de educación virtual se consideraban el temor o angustia como parte de las emociones al hacerle frente al uso de las TICs (Mejía, et. al, 2018), luego de los primeros meses de adaptación a las TICs los docentes pudieron manifestar actitudes favorables como satisfacción y gran beneficio (Flores, 2012) en cuanto a la planificación de las sesiones virtuales desenvolviéndose adecuadamente en el aula (remota), su vez se desprende un gran interés y motivación por parte de los docentes por la utilización y aprendizaje del uso de las TICs para incrementar la interacción con los estudiantes (Vargas, 2019) quienes tienen un buen manejo y uso de las mismas. Debido a que el uso de las TICs no ha sido útil para el desempeño docente en cuanto a actividades en el colegio (Fernández, 2002), no existe un interés o motivación por su uso, por ello se obtuvo una relación negativa.

La hipótesis específica orientada a la asociación positiva entre actitud conductual y evaluación de desempeño en el aula e interacción con los estudiantes recibió respaldo, mientras que la asociación positiva entre actitud hacia el uso de las TICs y autoevaluación de las labores escolares no recibió respaldo. La actitud conductual se relaciona al apoyo que siente el docente mediante la integración de las TICs en su quehacer pedagógico (Granda, 2018), por el contexto de pandemia en el que nos encontramos, el sector educativo, específicamente los docentes fueron obligados a integrar como práctica pedagógica el uso de las TICs, a su vez estas favorecen su desempeño (Enciso, 2020), por lo que los docentes tienen en cuenta sus ventajas como herramienta educativa (Mejía, et. al, 2018) en el proceso de enseñanza, así mismo existe una disposición para su total integración ya que apoya mucho la vinculación interpersonal con los estudiantes, 
clarificando algunas dudas que puedan surgir en las sesiones virtuales (Fernández, 2002), por el contrario, su integración se encuentra relacionada negativamente con su desempeño con relación a la vida en el colegio, ya que esta no se ve afectada por el uso de recursos tecnológicos e informáticos.

Las limitaciones presentadas del estudio apuntan a la escasez de antecedentes del fenómeno estudiado dentro de artículos científicos con población del Perú, en su mayoría se hallaron trabajos con poca rigurosidad científica (tesis). Además, los instrumentos que pudieron evaluar específicamente estas variables en el contexto de pandemia por COVID19 fueron escasos. Otra limitación se evidenció por las dificultades en el acceso a los participantes y por el uso de un muestreo no probabilístico por conveniencia, donde solo participaron docentes beneficiarios de forma voluntaria por lo que no se trataría de un grupo representativo de docentes del país. A pesar de estas limitaciones, se propuso una aplicación novedosa de carácter cuantitativo, que relaciona el contexto actual de pandemia y la percepción del desempeño de uno de los primeros grupos de batalla que hace frente al COVID-19, como son los docentes frente a las herramientas tecnológicas con las que disponen para el desarrollo de sus clases.

\section{Conclusiones}

Los resultados de este estudio permitieron llegar a las siguientes conclusiones:

- Se determinaron niveles medios y altos de actitud hacia el uso de las TICs en docentes de Lima en confinamiento por COVID-19, relacionado a la disponibilidad y conocimiento de estas.

- Se determinó una baja percepción de desempeño en docentes de Lima en confinamiento por COVID-19, relacionado a las limitaciones que se presentaron debido al cambio del método de enseñanza. 
- Se encontró una asociación positiva entre la actitud global hacia las TICs y las dimensiones del desempeño autopercibido como: evaluación de desempeño en el aula e interacción con los estudiantes, no así con autoevaluación de las labores escolares, que demostró una asociación negativa, debido a que el contexto no permitió la interacción del docente con colegas y otras actividades extracurriculares.

- Se encontró una asociación positiva entre desempeño autopercibido y las dimensiones de la variable actitud, tales como: cognitiva, actitud afectiva y actitud conductual, ya que por la actual coyuntura estas herramientas han permitido que el docente pueda ejecutar sus actividades profesionales a favor de la educación.

- Se encontró una asociación positiva entre la actitud cognitiva hacia el uso de las TICs y las dimensiones del desempeño autopercibido como: evaluación del desempeño en el aula e interacción con los estudiantes, no así con autoevaluación de las labores escolares, debido a que el conocimiento sobre el uso y manejo de las Tics en el proceso de enseñanza, mejora a su vez su desempeño e interacción con sus estudiantes.

- Se encontró una asociación positiva entre actitud afectiva hacia el uso de las TICs y las dimensiones del desempeño autopercibido como: evaluación de desempeño en el aula e interacción con los estudiantes, debido a que una actitud favorable a estos recursos permite una mayor interacción con los mismos permitiendo una mejor presentación y desempeño docente, no así con autoevaluación de las labores escolares.

- Se encontró una asociación positiva entre actitud conductual hacia el uso de las TICs y las dimensiones de desempeño autopercibido como: evaluación de desempeño en el aula e interacción con los estudiantes, no así con autoevaluación de las labores escolares, debido a que el control y manejo de estos recursos tecnológicos permite desarrollar (en este contexto) una adecuada clase, dinámica e interactiva a favor de la educación de los estudiantes. 
El análisis preliminar de la confiabilidad determinó que es conveniente eliminar cuatro ítems respecto a la dimensión actitud afectiva y tres ítems de la dimensión actitud conductual de la variable actitud hacia el uso de las TICs y dos ítems de la dimensión interacción con los estudiantes de la variable desempeño autopercibido, debido a que las respuestas de estos ítems no presentaron homogeneidad con los demás ítems de cada dimensión mencionada, pudiéndose relacionar a factores externos como las condiciones de aplicación de los mismos instrumentos, al realizarse de manera virtual y ser ambas pruebas largas, pudieron haberse marcado otras respuestas para esas preguntas.

Los resultados mostrados en la presente investigación contribuyen al conocimiento científico dentro del marco educativo actual de pandemia en cuanto a los resultados obtenidos respecto a los niveles y asociación de las variables, además de las condiciones de trabajo en la que los docentes de educación básica regular desempeñan su rol profesional, pues la ficha sociodemográfica refleja las limitaciones de espacio, acceso a recursos digitales y uso de los mismos a tiempo completo lo que impactó en el proceso de enseñanza durante los primeros ocho meses de pandemia. Los niveles medios y bajo respecto al uso de las TICs y la autoevaluación de su desempeño llaman a la reflexión del desafío de aprendizaje acelerado sobre tecnologías frente al entorno virtual. Finalmente, la asociación positiva de las variables del estudio muestra la importancia de una buena actitud, cognitiva, afectiva y conductual de las TICs y el desempeño del docente de gestión pública, desde la planificación de las sesiones hasta la interacción con los alumnos a través de las pantallas, para cumplir con el servicio de educación lo más excepcional posible, considerando las condiciones actuales de pandemia, limitación de recursos y poco tiempo para una buena adaptación virtual. 


\section{Recomendaciones}

En cuanto a la dimensión de investigación, se recomienda potenciar el marco del estudio realizado en futuras investigaciones con diseños predictivos complejos relacionados al contexto actual, una vez terminada la pandemia o el aislamiento social obligatorio, debido a que la actitud hacia el uso de las TICs y el desempeño autopercibido pueden haber sido afectadas por otros factores a lo largo del confinamiento, por lo que se sugiere relacionarla con otras variables psicológicas como: ansiedad y estrés generado por el uso de las TICs en situación de confinamiento e implicancias de la pandemia en el desempeño docente.

A nivel de generación de tecnologías, se sugiere impulsar el diseño y construcción de nuevos instrumentos que midan actitudes y competencias profesionales en los docentes, estos con propiedades psicométricas adaptadas a nuestra población y a la modalidad remota.

A nivel de procesamiento muestral, se recomienda utilizar un diseño probabilístico y estratificado, para garantizar la generalización de los resultados; así como ampliar el tamaño de la muestra, esto demostraría una mayor representatividad de la población solicitada.

En cuanto a las estrategias de aplicación y recojo de datos de manera remota, se sugiere buscar estrategias que impulsen una mayor interacción entre evaluador y evaluados con el fin de controlar los sesgos en sus respuestas, producto de la falta de reflexión o distracción.

Para la formación docente en competencias tecnológicas se sugiere impulsar estrategias de capacitación e integración sobre el uso de las TIC como apoyo en la autoevaluación del desempeño docente, generando la reflexión de las buenas prácticas y la corrección de acciones docentes poco funcionales, asimismo se sugiere impulsar el 
acompañamiento pedagógico reflexivo con el fin de generar un mayor compromiso y trabajo en equipo, situación mermada por las condiciones del trabajo remoto actual. 


\section{Referencias}

Ato, M., López, J. \& Benavente, A. (2013). Un sistema de clasificación de los diseños de investigación en psicología. Anales de Psicología, 29(3), 1038-1059. DOI: http://dx.doi.org/10.6018/analesps.29.3.178511

Baptista, P., Loeza, C., Almazán, A., López, V. \& Cárdenas, J. (2020). Encuesta Nacional a docentes ante el COVID-19. Retos para la educación a distancia. Revista Latinoamericana de Estudios Educativos, 50, 41-87. Recuperado de https://www.redalyc.org/jatsRepo/270/27063237021/html/index.html

Blink Learning. (2019). V Estudio sobre el uso de la tecnología en la educación. Informe de resultados Perú 2019. Recuperado de https://www.realinfluencers.es/wp-content/uploads/2020/05/BLINK-informe-TIC2019-PERU.pdf

Bolívar, C. (2012). La actitud del docente universitario hacia el uso educativo de las TIC: Conceptualización y medición. Paradigma, 33(2), 7-25. Recuperado de http://ve.scielo.org/pdf/pdg/v33n2/art02.pdf

Borda, M. \& Flores, G. (2018). Relación entre las competencias tecnológicas instrumentales y actitud hacia el uso de las TIC en docentes de la Institución Educativa San Antonio del Pedregal N40230, Arequipa-2018 (Tesis de Pregrado). Universidad Nacional de San Agustín de Arequipa, Perú. Recuperado de: http://repositorio.unsa.edu.pe/handle/UNSA/6647

Caballero, A. (2003). Factores como motivaciones para un buen desempeño laboral en los docentes de una escuela del nivel medio superior (Tesis de Maestría). Universidad Autónoma de Nueva León, Monterrey, México. Recuperado de: http://eprints.uanl.mx/id/eprint/5357 
Cabero, J. (1996). Nuevas tecnologías, comunicación y educación. Edutec. Revista Electrónica de Tecnología Educativa, (1). DOI: https://doi.org/10.21556/edutec.1996.1.576

Cabero, J. (2002). Mitos de la sociedad de la información: sus impactos en la educación. España: Kronos.

Cabrera, A. (2020). La educación virtual en tiempos de pandemia. Revista Juventud y ciencia solidaria: en el camino de la investigación, (5), 52-55. Recuperado de: http://dspace.ups.edu.ec/handle/123456789/18970

Cáceres, K. (2020). Educación virtual: Creando espacios afectivos de convivencia y aprendizaje en tiempos de Covid-19. Ciencia América, 9(2), 38-44. DOI: http://dx.doi.org/10.33210/ca.v9i2.284

Calvani, A., Cartelli, A., Fini, A. \& Ranieri, M. (2008). Models and instruments for assessing digital competence at school. Journal of E-learning and Knowledge Society, 4(3), 183-193. DOI: https://doi.org/10.20368/1971-8829/288

Chero, A. (2020). Utilización de las Tics y el desempeño docente en la Universidad Católica los Ángeles Chimbote - 2019 (Tesis doctoral). Universidad César Vallejo, Chimbote, Perú. Recuperado de: https://hdl.handle.net/20.500.12692/44472

Cherry, P. (2016). Influencia de la evaluación docente en el desempeño profesional de un profesor de lenguaje y comunicación. Concepción, Chile: Universidad Católica de la Santísima Concepción. Recuperado de: http://repositoriodigital.ucsc.cl/handle/25022009/1059

Colegio de Psicólogos del Perú (2018). Código de ética y deontología. Recuperado de http://api.cpsp.io/public/documents/codigo_de_etica_y_deontologia.pdf 
Comisión Económica para América Latina y Caribe (2020). Informe COVID -19: La educación en tiempos de pandemia de COVID-19. Recuperado de https://www.cepal.org/es/publicaciones/45904-la-educacion-tiempos-lapandemia-covid-19

Correa, Q. \& Patiño, J. (2016). Uso de las tecnologías de la información y la comunicación y el desempeño de los docentes de educación básica secundaria en la Institución Educativa Jorge Eliécer Gaitán Tota- Boyacá 2016 (Tesis de Maestría). Universidad Privada Norbert Wiener, Lima, Perú. Recuperado de http://repositorio.uwiener.edu.pe/handle/123456789/589

Cruz, M., Pozo, M., Aushay, H. \& Arias, A. (2018). Las Tecnologías de la Información y de la Comunicación (TIC) como forma investigativa interdisciplinaria con un enfoque intercultural para el proceso de formación estudiantil. E-Ciencias de la Información, 9(1). DOI: https://doi.org/10.15517/eci.v1i1.33052

Cubas, A. (2007). Actitudes hacia la lectura y niveles de comprensión lectora en estudiantes de sexto grado de primaria (Tesis de pregrado). Pontificia Universidad Católica del Perú. Lima, Perú. Recuperado de: http://hdl.handle.net/20.500.12404/427

De Pablos, J. (2010). Universidad y sociedad del conocimiento. Las competencias informacionales y digitales. Revista de Universidad y Sociedad del Conocimiento (RUSC), 7(2), 6-16. DOI: http://dx.doi.org/10.7238/rusc.v7i2.977

Diario El Peruano. (15 de marzo del 2020). Gobierno declara estado de emergencia nacional y aislamiento social obligatorio por 15 días. El Peruano. Recuperado de https://www.elperuano.pe/noticia-gobierno-declara-estado-emergencia-nacionaly-aislamiento-social-obligatorio-15-dias-92075.aspx 
Diario El Peruano. (11 de julio del 2020). Abnegada labor del profesorado. El Peruano. Recuperado de: https://elperuano.pe/noticia-abnegada-labor-del-profesorado99487.aspx

Diario Gestión. (6 de marzo de 2020). Coronavirus: Vizcarra confirma el primer caso en el Perú. Gestión. Recuperado de: https://gestion.pe/peru/coronavirus-en-peru$\underline{\text { martin-vizcarra-confirma-primer-caso-del-covid-19-en-el-pais-nndc- }}$ noticia/?ref=gesr

Diario Gestión. (16 de julio del 2020). ¿Zoom o Google Meet, qué app experimentó un mayor crecimiento durante la cuarentena en Perú? Gestión. Recuperado de: https://gestion.pe/tecnologia/zoom-o-google-meet-que-app-experimento-unmayor-crecimiento-durante-la-cuarentena-en-peru-nndc-noticia/

Diario Perú 21. (8 de septiembre del 2020). La importancia de la educación virtual y el futuro de los niños. Perú 21. Recuperado de https://peru21.pe/peru/la$\underline{\text { importancia-de-la-educacion-virtual-y-el-futuro-de-los-ninos-noticia/?ref=p21r }}$

Domínguez-Lara, S. (2017). Magnitud del efecto, una guía rápida. Educación Médica, 19(4), 251-254. DOI: 10.1016/j.edumed.2017.07.002

Enciso, M. (2020). Uso de las TIC en las competencias digitales de los docentes del Colegio 5074 Alcides Spelucín Vega, Callao, 2019 (Tesis de Maestría). Universidad César Vallejo, Lima, Perú. Recuperado de: https://hdl.handle.net/20.500.12692/42772

Espichán, M. (2017). Las tecnologías de la información y comunicación y el desempeño docente en la Facultad de Administración y Negocios de la Universidad Tecnológica, Lima, 2015 (Tesis de Maestría). Universidad Nacional de Educación Enrique Guzmán y Valle, Lima, Perú. Recuperado de: http://repositorio.une.edu.pe/handle/UNE/1544 
Espinosa, G. (2014). Desempeño docente en el proceso de enseñanza-aprendizaje en el nivel de Educación Básica Superior del Centro Educativo Colegio de Bachillerato Ciudad de Portovelo, del cantón Portovelo, Provincia de El Oro, en el año lectivo 2013-2014 (Tesis de licenciatura). Universidad Técnica Particular de Loja, Ecuador. Recuperado de: http://dspace.utpl.edu.ec/handle/123456789/11373

Fernández, M. (2002). Realidad Psicosocial del Maestro de primaria. Lima, Perú: Fondo de desarrollo editorial.

Flores, G. (2012). Actitudes hacia las Tecnologías de la comunicación de información y comunicación de los docentes de la Red Educativa $N^{\circ} 01$ Ventanilla-Callao (Tesis de Maestría). Universidad San Ignacio de Loyola, Lima, Perú. Recuperado de http://repositorio.usil.edu.pe/handle/123456789/1167

García, M. (2020). La docencia desde el hogar. Una alternativa necesaria en tiempos del Covid-19. Polo del conocimiento: Revista científico - profesional, 5(4), 304-324. Recuperado de https://dialnet.unirioja.es/servlet/articulo?codigo=7398376

Gil, E. (2002). Identidad y Nuevas Tecnologías. Recuperado de http:www.uoc.edu/web/esp art/gil 0902/htm

Granda, S. (2018). Relación entre la personalidad, estilo de enseñanza y actitud de los docentes hacia el uso de las Tecnologías de la información y comunicación en la enseñanza en el nivel secundario de instituciones educativas públicas del Sector Noreste del Distrito de Castilla-Piura-2106 (Tesis Doctoral). Universidad Nacional de Piura, Perú. Recuperado de: http://repositorio.unp.edu.pe/handle/UNP/2176

Hernández, R. (2017). Impacto de las TIC en la educación: Retos y Perspectivas. Propósitos y Representaciones, 5(1), 325-347. DOI: http://dx.doi.org/10.20511/pyr2017.v5n1.149 
Hernández, R. Fernández, C. \& Baptista, M. (2014). Metodología de la Investigación (6ta edición). México: McGRAW-HILL

Hidalgo, L. (2020). Competencias profesionales docentes en la educación remota. Revista Internacional Multidisciplinaria - Centro Internacional de Investigación y Desarrollo, 1 (1), 249-270. DOI: https://doi.org/10.46785/ciidj.v1i1.61

Ingaruca, S. (2020). Uso de TICS y competencia digital docente en la Institución Educativa Felipe Huamán Poma de Ayala - Chosica, 2019 (Tesis de Maestría). Universidad Cesar Vallejo, Lima, Perú. Recuperado de: https://hdl.handle.net/20.500.12692/43702

Instituto Nacional de Tecnologías Educativas y de Formación del Profesorado (2017). Marco común de competencia digital docente septiembre 2017. Recuperado de $\underline{\text { http://eduteka.icesi.edu.co/pdfdir/intef-competencia-digital-docente-2017.pdf }}$

Konca, A.S., Ozel, E. \& Zelyurt, H. (2016). Attitudes of preschool teachers towards using information and communication technologies (ICT). International Journal of Research in Education and Science (IJRES), 2(1), 10-15.

DOI: $\underline{10.21890 / \mathrm{ijres} .21816}$

Lechleiter, M. \& Vidarte, R. (6 de abril de 2020). El sistema educativo peruano: en busca de la calidad y equidad en tiempos de COVID-19. Blog de la Educación Mundial. Recuperado de:

https://educacionmundialblog.wordpress.com/2020/04/06/el-sistema-educativoperuano-en-busca-de-la-calidad-y-equidad-en-tiempos-de-covid-19/commentpage-1/

Lino, M. (2018). Influencia del uso de los tics en la evaluación del desempeño del docente en el sistema educativo universitario de Lima (Tesis de pregrado). 
Universidad San Ignacio de Loyola, Lima, Perú. Recuperado de:

http://repositorio.usil.edu.pe/handle/USIL/3613

Ludeña, E. (2019). Uso de las Tic y el desempeño docente en la facultad de Ciencias de la Empresa de la Universidad Continental (Tesis de Licenciatura). Universidad Continental, Huancayo, Perú. Recuperado de: https://hdl.handle.net/20.500.12394/6168

Magdaleno, A. \& Llopis, A. (2014). La actitud docente y el grado de uso de las TIC en la comunicación familia-escuela. Fórum de Recerca. Universidad Jaume.

Facultad de ciencias, humanidades y sociales, (19), 393 - 409. DOI: http://dx.doi.org/10.6035/ForumRecerca.2014.19.25

Mazza, D. (2020). Lo que la pandemia nos deja: una oportunidad para pensarnos como docentes. Centro de Innovación en tecnología y pedagogía, (7), 1-9. Recuperado de: http://www.fvet.uba.ar/sites/default/files/pictures/campus/19pandemia.pdf

Martínez-Garcés, J. \& Garcés-Fuenmayor, J. (2020). Competencias digitales docentes y el reto de la educación virtual derivado de la COVID-19. Educación y Humanismo, 22(39), 1-16. DOI: https://doi.org/10.17081/eduhum.22.39.4114 Mejía, A., Silva, C., Villarreal, C., Suarez, D. \& Villamizar, C. (2018). Estudio de los factores de resistencia al cambio y actitudes hacia el uso educativo de las TIC por parte del personal docente. Revista Boletín Redipe (Red Iberoamericana de Pedagogía), 7(2), 53-63. Recuperado de: https://revista.redipe.org/index.php/1/article/view/428

Mendoza, C. \& Lukis, K. (2020). Actitudes de los Docentes en el Uso de las Tecnologías de la Información y Comunicación (TIC) en la Práctica Pedagógica de una Institución de Educación Superior Privada de la Ciudad de Lima, 2019 
(Tesis de maestría). Universidad Tecnológica del Perú, Lima, Perú. Recuperado de: http://repositorio.utp.edu.pe/handle/UTP/3193

Meléndez-Ferrer, L. \& Canquiz, L. (2003). La actitud del profesor universitario desde una perspectiva pedagógica, en el marco de la relación universidad-empresa. Revista de Pedagogía, 24(71), 417-445. Recuperado de: http://ve.scielo.org/scielo.php?script=sci_arttext\&pid=S079897922003000300004\&lng=es\&tlng=es.

Ministerio de Educación del Perú. (14 de julio 2020). Ministro Benavides: “Aprendo en casa ha llegado para quedarse" (Nota de prensa). Recuperado de: https://www.gob.pe/institucion/minedu/noticias/208830-ministro-benavidesaprendo-en-casa-ha-llegado-para-quedarse

Ministerio de Educación del Perú. (2012). Marco de Buen Desempeño Docente. Para mejorar tu práctica como maestro y guiar el aprendizaje de tus estudiantes. Recuperado de: http://www.minedu.gob.pe/pdf/ed/marco-de-buen-desempenodocente.pdf

Molas, N. \& Rosselló, M. (2010). Revolución en las aulas: llegan los profesores del siglo. La introducción de las TIC en las aulas y el nuevo rol docente. Didáctica, innovación y multimedia, (19), 1-9. Recuperado de: https://www.raco.cat/index.php/DIM/article/view/214711

Myers, D. (2000). Psicología Social. México: McGraw-Hill Interamericana.

Naranjo, M. (2010). Factores que favorecen el desarrollo de una actitud positiva hacia las actividades académicas. Revista Educación, 34(1), 31-53. Recuperado de: https://www.redalyc.org/articulo.oa?id=440/44013961002

Olivera, J. (2015). Recursos informáticos y desempeño docente en la Facultad de Ingeniería de la Universidad Peruana Los Andes Filial Lima -2015 (Tesis de 
Pregrado). Universidad Peruana Los Andes, Huancayo, Perú. Recuperado de: http://repositorio.upla.edu.pe/handle/UPLA/132

Ormaza, M. \& Rodríguez, M. (2020). El impacto de las TIC en el sistema educativo.

Revista Atlante: Cuadernos de Educación y Desarrollo. Recuperado de:

https://www.eumed.net/rev/atlante/2020/05/tic-sistema-educativo.html

Organización de las Naciones Unidas para la Educación, la Ciencia y la Cultura

(UNESCO). (2020). Enseñar en tiempos de COVID-19: Una guía teórico-práctica para docentes. Recuperado de https://en.unesco.org/news/ensenar-tiempos-covid$\underline{19}$

Organización Mundial de la Salud (2020). Brote de enfermedad por coronavirus (COVID-19). Recuperado de https://www.who.int/es/emergencies/diseases/novelcoronavirus-2019?gclid=CjwKCAiA_9r_BRBZEiwAHZ_v19SIQ-iHtvyAl0TUFyg2gam5bQTHfOuTqS0J110CL_XjogzVWX_cxoCcMQQAvD_BwE

Otzen, T. \& Manterola, C. (2017). Técnicas de Muestreo sobre una Población a Estudio. International Journal of Morphology, 35(1), 227 232. DOI: https://dx.doi.org/10.4067/S0717-95022017000100037

Oskamp, S. (1991). Attitudes and Opinions. Englewood Cliffs, N. J.: Prentice- Hall. Oyarce, M. (2016). Tecnologías de información y comunicación, TIC y su relación con el desempeño docente con calidad en la Escuela Académica Profesional de Comunicación Social de la Universidad Nacional Mayor de San Marcos (Tesis de maestría). Universidad Nacional Mayor de San Marcos, Lima, Perú. Recuperado de: https://hdl.handle.net/20.500.12672/4961

Padilla, S. (2018). Usos y actitudes de los formadores de docentes ante las TIC. Entre lo recomendable y la realidad de las aulas. Apertura (Guadalajara, Jal.), 10(1), 132148. DOI: https://doi.org/10.32870/ap.v10n1.1107 
Padrón, M. (2008). Dificultades de los docentes en formación para el uso de las tecnologías de la información y la comunicación (TIC) en el proceso de investigación en la asignatura trabajo especial de grado. Revista de Tecnología de Información y Comunicación en Educación, 2(2), 135-152. Recuperado de http://servicio.bc.uc.edu.ve/educacion/eduweb/vol2n2/art7.pdf

Paredes, L. (2008). Las tecnologías de información y comunicación (tic) y su relación con el desempeño docente en la institución educativa 40029 "ludwing van beethoven", alto selva alegre 2017. (Tesis maestría). Universidad Nacional de San Agustín de Arequipa. Recuperado de: http://repositorio.unsa.edu.pe/handle/UNSA/6584

Pérez, M. \& Tramallino, C. (2020). Las consecuencias educativas y el desarrollo del docente a causa del uso de las Tics en las reformas y tipos de aprendizaje en tiempos del COVID-19. Magazine de las Ciencias: Revista de investigación e innovación 5 (7), 30-44. Recuperado de https://revistas.utb.edu.ec/index.php/magazine/article/view/900/681

Picón, G., González de Caballero, G. \& Paredes, J. (2020). Desempeño y formación docente en competencias digitales en clases no presenciales durante la pandemia COVID-19. Recuperado de: https://preprints.scielo.org/index.php/scielo/preprint/download/778/1075/1115\&sa =U\&ved=2ahUKEwijw86Vg9_qAhWwiOAKHT4hA0QFjAAegQIAxAB\&usg=AOvVaw12DJ-3ehzIcgOd-sg5VYTb

Ponterotto, J.\& Ruckdeschel, D. (2007). An Overview of Coefficient Alpha and a Reliability Matrix for Estimating Adequacy of Internal Consistency Coefficients with Psychological Research Measures. Perceptual and Motor Skills, 105(3), 9971014. DOI: https://doi.org/10.2466/pms.105.3.997-1014 
Ravines, M. (26 de abril de 2020). Covid-19: Resumen de las principales medidas adoptadas por el Gobierno para combatirlo [Punto Seguido]. Recuperado de https://puntoseguido.upc.edu.pe/covid-19-resumen-de-las-principales-medidasadoptadas-por-el-gobierno-para-combatirlo/

Resolución Ministerial № 149-2020-MINEDU. Diario Oficial El Peruano, Lima, Perú, 13 marzo de 2020. Recuperado de: https://www.gob.pe/institucion/minedu/normas-legales/460465-149-2020-minedu Resolución Ministerial, № 160, 2020-MINEDU. Diario Oficial El Peruano, Lima, Perú, 1 de abril de 2020. Recuperado de:

https://www.gob.pe/institucion/minedu/normas-legales/466108-160-2020-minedu

Resolución Viceministerial N 079-2020-MINEDU. Diario Oficial El Peruano, Lima, Perú, 12 marzo de 2020. Recuperado de: https://www.gob.pe/institucion/minedu/normas-legales/459956-079-2020-minedu

Rojas, A. \& Ávila, Y. (2019). El uso de las TIC como recurso para la autosuperación del profesional de la educación. Revista dilemas contemporáneos: educación, política y valores, 6(3), 1-24. Recuperado de: https://www.dilemascontemporaneoseducacionpoliticayvalores.com/index.php/dil emas/article/download/1828/1955/

Román, GC, Spencer, PS, Reis, J., Buguet, A., Faris, M., Katrak, SM, Láinez, M., Medina, MT, Meshram, C., Mizusawa, H., Öztürk, S., Wasay, M. \& WFN Environmental Neurology Specialty Group (2020). La neurología de COVID-19 revisada: una propuesta del Grupo de Especialidad en Neurología Ambiental de la Federación Mundial de Neurología para implementar registros neurológicos internacionales. Revista de ciencias neurológicas, 414, 116884. DOI: https://doi.org/10.1016/j.jns.2020.116884 
Rosario, J. (2005). La Tecnología de la Información y la Comunicación (TIC). Su uso como herramienta para el fortalecimiento y el desarrollo de la educación virtual, revisado el 20 de mayo 2009. Recuperado de: https://ddd.uab.cat/pub/dim/16993748n8/16993748n8a6.pdf.

Rosales, C. (2014). Actitud de los maestros de primaria de la institución privada de Santa Catarina Pínula frente a las nuevas tecnologías de la información y la comunicación en la labor docente (Tesis de pregrado). Universidad Rafael Landívar, Guatemala. Recuperado de: http://biblio3.url.edu.gt/Tesario/2014/05/84/Rosales-Claudia.pdf

Sánchez, M., Martínez, A., Torres, R., De Agüero, M., Hernández, A., Benavides, M., Rendón, J. \& Jaimes, C. (2020). Retos educativos durante la pandemia de covid19: una encuesta a profesores de la UNAM. Revista Digital Universitaria, 21(3), 1-24. DOI: http://doi.org/10.22201/codeic.16076079e.2020.v21n3.a12.

Sánchez, S. \& Mesa, C (1997). Actitudes hacia la tolerancia y la cooperación en ambientes multiculturales. [Documento en Línea]. Recuperado de: http://www.ugr.es/ eirene/eirene/ eirene9cap1.pdf

Sandoval, C. (2020). La Educación en Tiempo del Covid-19 Herramientas TIC: El Nuevo Rol Docente en el Fortalecimiento del Proceso Enseñanza Aprendizaje de las Prácticas Educativas Innovadoras. Revista Tecnológica-Educativa Docentes 2.0, 9 (2), 24-31. DOI: https://doi.org/10.37843/rted.v9i2.138

Saravia, E. (2019). Desempeño docente y satisfacción del estudiante en el nivel secundario I. E. E. Luis Fabio Xammar Jurado. (Tesis de Pregrado). Universidad Nacional José Faustino Sánchez Carrión, Huacho, Lima. Recuperado de: http://repositorio.unjfsc.edu.pe/handle/UNJFSC/3789 
Shum, Y. (27 de julio 2020). Covid -19 digital, internet, social media en el mundo [Blog]. Recuperado de https://yiminshum.com/internet-digital-covid-19-2020.

Socolovsky, Y. (2020). Preguntas a la coyuntura. Reflexiones, problemas y preocupaciones acerca del trabajo docente, el uso de las tecnologías y las desigualdades ante la pandemia. Trayectorias Universitarias, 6(10), 1-8. Recuperado de: https://revistas.unlp.edu.ar/TrayectoriasUniversitarias/article/view/10428

Tapia, H. (2018). Actitud hacia las TIC y hacia su integración didáctica en la formación inicial docente. Actualidades Investigativas en Educación, 18(3), 702-731. DOI: https://dx.doi.org/10.15517/aie.v18i3.34437

Tello, E. (2011). Las tecnologías de la información y comunicaciones (TIC) y la brecha digital: su impacto en la sociedad de México. Revista de Universidad y Sociedad del Conocimiento, 4(2). Recuperado de https://rusc.uoc.edu/rusc/es/index.php/rusc/article/download/v4n2-tello/3051221-2-PB.pdf

The Jamovi project (2020). Jamovi. (Version 1.2) [Computer Software]. https://www.jamovi.org.

Valdés, H. (2000). “¿Cómo evaluar?”. Ponencia presentada en el Encuentro Iberoamericano sobre Evaluación del Desempeño Docente. México, OEI. Documento de trabajo. Recuperado de: https://rieoei.org/RIE

Valdés, H. (2006). Evaluación del Desempeño docente. Ponencia presentada por Cuba. Encuentro Iberoamericano sobre Evaluación del Desempeño Docente. Recuperado de: http://www.campus-oei.org/de/rifad01.htm 
Vargas, A. (2019). Las TIC y el desempeño docente en la Institución Educativa $N^{\circ} 1228$ Leoncio Prado Gutiérrez-Ate. (Tesis de Licenciatura). Universidad Cesar Vallejo, Lima, Perú. Recuperado de: https://hdl.handle.net/20.500.12692/39379 Vilcahuamán, W. (2019). Las competencias digitales y el nivel de actitudes frente a las Tic de los docentes del SENATI Cusco (Tesis de Maestría). Universidad Peruana Cayetano Heredia, Cusco, Perú. Recuperado de: http://repositorio.upch.edu.pe/handle/upch/8507

Villén, C. (2020). El profesorado y las tecnologías en tiempos de confinamiento por la pandemia Covid-19. Creencias sobre actitudes, formación, competencia digital e importancia de las TIC en educación. Recuperado de:

http://hdl.handle.net/10366/143691

Whittaker, J. \& Sandra. J. (1986). Psicología. 4ta. Edic. México. Interamericana S.A.

Worchel, S., Cooper, J., Goethals, G. \& Olson (2002), Psicología social. México. International Thomson Editores. S.A. DE C.V.

Zimbardo, P. \& Leippe, R. (1991). The psychology of attitude change and social. New York: McGraw-Hill 


\section{Anexos}

\section{Anexo 1.1: Consentimiento Informado}

Estimado/a docente:

La investigación titulada "Actitud hacia el uso de las TIC y desempeño autopercibido en docentes de Lima Metropolitana durante el confinamiento por Covid-19” es conducida por:

- Karina Choquecota Quinta

Bachiller en Psicología

Universidad San Ignacio de Loyola

Correo electrónico: karina.choquecota@usil.pe

- Escarle Jomeine Quispe Livias

Bachiller en psicología

Universidad San Ignacio de Loyola

Correo electrónico: escarle.quispe @usil.pe

- Carmen Magali Meléndez Jara

Magíster en psicología

Universidad Nacional Mayor de San Marcos

Correo electrónico: carmen.melendez@epg.usil.pe

Este estudio tiene como objetivo evaluar a docentes que laboran en instituciones educativas y realizan trabajo remoto con la finalidad de identificar su actitud hacia el uso de tecnologías de la información como estrategia de enseñanza y el desempeño autopercibido en su rol como docente. Por ello, su participación es primordial en este proceso y estaremos agradecidas si accede.

La duración de toda la evaluación será no mayor a 15 minutos. Se solicitarán datos personales (sexo, edad, etc.) así como la respuesta a encuestas que valoran aspectos psicológicos (p.e., actitudes y desempeño). La información recopilada se tratará en forma confidencial. Toda la información se usará para fines del estudio y sin ningún otro propósito.

El proceso es completamente voluntario y puede interrumpir su participación cuando lo considere pertinente.

Usted declara (marcar ambas opciones)

$\square$ Ser mayor de edad (18 o más años)

$\square$ Participar en este estudio 
Anexo 1.2: Ficha sociodemográfica

\begin{tabular}{|c|c|}
\hline $\begin{array}{l}\text { Edad __años } \\
\text { Sexo } \\
\text { Mujer } \\
\text { Hombre } \\
\text { Prefiero no decirlo }\end{array}$ & $\begin{array}{l}\text { ¿Qué dispositivos electrónicos usa para } \\
\text { trabajar? (Puede marcar más de una } \\
\text { opción) } \\
\text { Celular } \\
\text { Tablet } \\
\text { Computadora de escritorio } \\
\text { Laptop } \\
\text { Cabina de internet } \\
\text { Otros }\end{array}$ \\
\hline $\begin{array}{l}\text { Lugar de trabajo remoto: } \\
\text { Lima Metropolitana } \\
\text { Fuera de Lima } \\
\text { Nivel de enseñanza } \\
\text { Inicial } \\
\text { Primaria } \\
\text { Secundaria }\end{array}$ & $\begin{array}{l}\text { Número de dispositivos electrónicos } \\
\text { (celular, Tablet, laptop, computadora, } \\
\text { etc) con los que cuenta en casa para } \\
\text { trabajar: } \\
1 \\
2 \\
3 \\
4 \\
5\end{array}$ \\
\hline $\begin{array}{l}\text { Gestión educativa } \\
\text { Pública } \\
\text { Privada }\end{array}$ & $\begin{array}{l}\text { Número de personas con las que } \\
\text { comparte los dispositivos electrónicos } \\
\text { (referidos anteriormente) para el } \\
\text { desarrollo de clases. } \\
1 \\
2 \\
3 \\
4 \\
5\end{array}$ \\
\hline 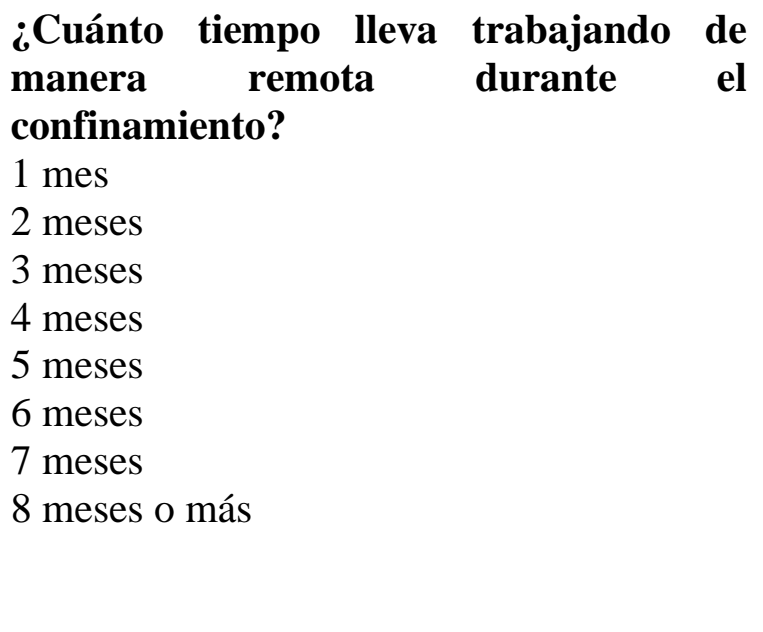 & $\begin{array}{l}\text { Herramienta digital que suele usar para } \\
\text { el desarrollo de sus clases. (Puede marcar } \\
\text { más de una opción) } \\
\text { Google Classroom } \\
\text { Google Meet } \\
\text { Microsoft Teams } \\
\text { Cisco Webex } \\
\text { EdModo } \\
\text { Zoom } \\
\text { Skype } \\
\text { Telegram } \\
\text { Jitsi Meet } \\
\text { WhatsApp }\end{array}$ \\
\hline
\end{tabular}




\section{Anexo 1.3: Escala actitud del uso de las Tecnologías de Información y Comunicación (TIC) en la enseñanza (Granda, 2018)}

En la siguiente Escala de Actitud, Ud. Encontrará una serie de afirmaciones respecto al uso de las Tic en los procesos de enseñanza. Todas las respuestas son válidas, sea usted lo más sincero y responda según su apreciación personal. Las alternativas que encontrará son las siguientes:

$\mathrm{A}=$ rechazo total $; \mathrm{B}=$ rechazo $; \mathrm{C}=$ indiferente $; \mathrm{D}=$ aceptación $; \mathrm{E}=$ aceptación total

\begin{tabular}{|c|c|c|c|c|c|}
\hline \multirow{2}{*}{ ITEMS } & \multicolumn{5}{|c|}{ ALTERNATIVAS } \\
\hline & A & $\mathrm{B}$ & $\mathrm{C}$ & $\mathrm{D}$ & $\mathrm{E}$ \\
\hline $\begin{array}{l}\text { 1.- Los conocimientos que tengo sobre las Tic son importantes para mí } \\
\text { desenvolvimiento profesional. }\end{array}$ & & & & & \\
\hline 2.- Me siento incomoda(o) con el uso de las Tic en el aula. & & & & & \\
\hline 3.-Me resulta fácil usar las Tic en mi trabajo en el aula. & & & & & \\
\hline $\begin{array}{l}\text { 4. El uso de las Tic permite aprender a buscar y recoger información } \\
\text { pertinente. * }\end{array}$ & & & & & \\
\hline 5.- Aprender sobre las Tic no es algo que me motive realmente. & & & & & \\
\hline $\begin{array}{l}\text { 6.- Siento que es de mucha utilidad el uso de las Tic para el trabajo escolar } \\
\text { con adolescentes. }\end{array}$ & & & & & \\
\hline 7.- Para mi trabajo es una ayuda excelente el uso de las Tic & & & & & \\
\hline 8.- En verdad el uso de las Tic en el aula me atemoriza. * & & & & & \\
\hline $\begin{array}{l}\text { 9.- Siento impaciencia cuando uso las Tic porque son un distractor en el } \\
\text { aula. }\end{array}$ & & & & & \\
\hline 10.- El interés de mis alumnos en el uso de las Tic me alienta a superarme. & & & & & \\
\hline 11.- Me agrada presentar material educativo usando las Tic. & & & & & \\
\hline $\begin{array}{l}\text { 12.- Hay demasiada información para recoger con las Tic, es muy } \\
\text { complicado enseñar de ese modo.* }\end{array}$ & & & & & \\
\hline 13.- El uso de las Tic demandan mucho tiempo que no dispongo. & & & & & \\
\hline $\begin{array}{l}\text { 14.- El uso de las Tic me permite actualizarme permanentemente en todo } \\
\text { aspecto. }\end{array}$ & & & & & \\
\hline $\begin{array}{l}\text { 15.- Usando las Tic se puede avanzar en el desarrollo de los cursos de } \\
\text { manera más eficiente. }\end{array}$ & & & & & \\
\hline
\end{tabular}


16.- El uso de las Tic me ha permitido saber más sobre editar textos, el uso de navegadores, hoja de cálculo, etc. y usar ese conocimiento para mejorar mi trabajo.

17.- Los/ las estudiantes saben mucho sobre las Tic, eso me preocupa. *

18.- Me divierte aprender sobre las Tic, es muy estimulante. *

19.- El uso de las Tic posibilita en el docente y alumno realizar trabajo escolar cooperativo.

20.- No es importante conocer sobre las Tic si sabes hacer tu trabajo.

21.- Conocer sobre Tic me permite usar con mayor facilidad el e-mail y redes sociales para comunicarme con mis colegas y estudiantes.

22.- Siento que he mejorado mucho en mi vida aprendiendo sobre el uso de las Tic para diversos temas y aspectos.

23.- Mi material de trabajo ha mejorado mucho con el uso de las Tic.

24.- Las Tic solo ayudan en algunas asignaturas.

25.- Tengo la impresión de que las Tic son peligrosas para la salud mental de los/las estudiantes. *

26.- Siento gran satisfacción profesional cuando logro que mis alumnos se interesen en las clases desarrolladas con las Tic.

27.- Preparar el material de trabajo demanda demasiado tiempo.

28.-Considero que tengo los saberes suficientes para desarrollar mis clases usando las Tic.

29.- No es para mí el uso de las Tic en el aula, avanzo muy lento.

30.- Los/las estudiantes prefieren trabajar con la computadora que escuchar al profesor. *

\section{Nota: * items eliminados}




\section{Anexo 1.4: Cuestionario de autorreporte del desempeño docente (Fernández, 2002)}

A continuación, se presenta un conjunto de diferentes situaciones que tratan sobre diversos aspectos de su actividad docente. Indíquenos la frecuencia con que presentan dichos aspectos, para ello debe utilizar la siguiente escala:

\section{Nunca $=1$ Casi Nunca $=2$ A veces $=3$ En duda $=4$ Ocasionalmente=5 Casi siempre $=6$ Siempre $=7$}

Recuerde que no hay respuestas correctas. Trate de presentar la respuesta que le resulte natural, contestando rápidamente a todas las preguntas.

\begin{tabular}{|l|c|c|c|c|c|c|c|}
\hline \multicolumn{1}{|c|}{ ÍTEMS } & \multicolumn{5}{|c|}{ ALTERNATIVAS } \\
\hline 1.- Las clases que realizo son entretenidas. & 1 & 2 & 3 & 4 & 5 & 6 & 7 \\
\hline $\begin{array}{l}\text { 2.- Puedo identificar las características personales de cada } \\
\text { uno de mis alumnos. }\end{array}$ & 1 & 2 & 3 & 4 & 5 & 6 & 7 \\
\hline $\begin{array}{l}\text { 3.- Tengo capacidad para planificar adecuadamente las } \\
\text { clases. }\end{array}$ & 1 & 2 & 3 & 4 & 5 & 6 & 7 \\
\hline $\begin{array}{l}\text { 4.- Mis clases se desarrollan en un ambiente adecuado. } \\
\text { 5.- En las clases utilizo diferentes estrategias didácticas. }\end{array}$ & 1 & 2 & 3 & 4 & 5 & 6 & 7 \\
\hline $\begin{array}{l}\text { 6.- En mis clases aplico lo que aprendí en la universidad o } \\
\text { instituto. }\end{array}$ & 1 & 2 & 3 & 4 & 5 & 6 & 7 \\
\hline $\begin{array}{l}\text { 7.- Conozco como va el rendimiento académico de cada } \\
\text { uno de mis alumnos. }\end{array}$ & 1 & 2 & 3 & 4 & 5 & 6 & 7 \\
\hline $\begin{array}{l}\text { 8.- En las clases mis alumnos desarrollan sus valores. } \\
\text { 9.- Soy objetivo cuando calificó a los alumnos. }\end{array}$ & 1 & 2 & 3 & 4 & 5 & 6 & 7 \\
\hline $\begin{array}{l}\text { 10.- Todo lo que aprendo lo aplico en mis clases. } \\
\text { 13.- Los alumnos tienen un bajo rendimiento. * }\end{array}$ & 1 & 2 & 3 & 4 & 5 & 6 & 7 \\
\hline $\begin{array}{l}\text { 11.- Ayudo a mis alumnos a que conozcan sus derechos. } \\
\text { claridad. }\end{array}$ & 1 & 2 & 3 & 4 & 5 & 6 & 7 \\
\hline 15.- Llego tarde al colegio (sesiones) & 1 & 2 & 3 & 4 & 5 & 6 & 7 \\
\hline
\end{tabular}




\begin{tabular}{|c|c|c|c|c|c|c|c|}
\hline $\begin{array}{l}\text { 16.- Aplicó en las clases lo que he aprendido en mi } \\
\text { experiencia }\end{array}$ & 1 & 2 & 3 & 4 & 5 & 6 & 7 \\
\hline $\begin{array}{l}\text { 17.- Los alumnos se aburren y distraen en las clases, por } \\
\text { ello les tengo que llamar la atención. }\end{array}$ & 1 & 2 & 3 & 4 & 5 & 6 & 7 \\
\hline $\begin{array}{l}\text { 18.- Trato de expresarme apropiadamente con los gestos } \\
\text { que hago. }\end{array}$ & 1 & 2 & 3 & 4 & 5 & 6 & 7 \\
\hline 19.- hay temas que necesito mejorar. & 1 & 2 & 3 & 4 & 5 & 6 & 7 \\
\hline $\begin{array}{l}\text { 20.- En mis clases los alumnos saben cuáles son los valores } \\
\text { nacionales. }\end{array}$ & 1 & 2 & 3 & 4 & 5 & 6 & 7 \\
\hline 21.- Me preocupo por el rendimiento de los alumnos. & 1 & 2 & 3 & 4 & 5 & 6 & 7 \\
\hline $\begin{array}{l}\text { 22.- Tengo dificultades para planificar las actividades que } \\
\text { debo desarrollar en clase. }\end{array}$ & 1 & 2 & 3 & 4 & 5 & 6 & 7 \\
\hline 23.- Trato de que mis clases sean interesantes. & 1 & 2 & 3 & 4 & 5 & 6 & 7 \\
\hline 24.- Me cuestiono acerca de mi vocación pedagógica. & 1 & 2 & 3 & 4 & 5 & 6 & 7 \\
\hline 25.- Los alumnos me preguntan después de clase. $*$ & 1 & 2 & 3 & 4 & 5 & 6 & 7 \\
\hline $\begin{array}{l}\text { 26.- Trato de actuar con justicia en las cosas que ocurren } \\
\text { en el aula. }\end{array}$ & 1 & 2 & 3 & 4 & 5 & 6 & 7 \\
\hline 27.- Cuando hay dificultades trato de ser realista. & 1 & 2 & 3 & 4 & 5 & 6 & 7 \\
\hline $\begin{array}{l}\text { 28.- Las actividades que realizó en el colegio me dejan } \\
\text { insatisfecho }\end{array}$ & 1 & 2 & 3 & 4 & 5 & 6 & 7 \\
\hline 29.- Llegó tarde al trabajo. & 1 & 2 & 3 & 4 & 5 & 6 & 7 \\
\hline 30.- Mis calificaciones son subjetivas. & 1 & 2 & 3 & 4 & 5 & 6 & 7 \\
\hline $\begin{array}{l}\text { 31.- Asisto a las reuniones de coordinación docente en el } \\
\text { colegio. }\end{array}$ & 1 & 2 & 3 & 4 & 5 & 6 & 7 \\
\hline 32.- Asisto a cursos, programas y talleres de capacitación. & 1 & 2 & 3 & 4 & 5 & 6 & 7 \\
\hline $\begin{array}{l}\text { 33.- Mis ideas son tomadas en cuenta por la dirección del } \\
\text { colegio. }\end{array}$ & 1 & 2 & 3 & 4 & 5 & 6 & 7 \\
\hline $\begin{array}{l}\text { 34.- Las tareas que me encomiendan las hago como creo } \\
\text { conveniente. }\end{array}$ & 1 & 2 & 3 & 4 & 5 & 6 & 7 \\
\hline 35.- Es difícil cumplir con las normas del colegio. & 1 & 2 & 3 & 4 & 5 & 6 & 7 \\
\hline 36.- La mayoría de los alumnos alcanzan buenas notas. & 1 & 2 & 3 & 4 & 5 & 6 & 7 \\
\hline
\end{tabular}




\begin{tabular}{|l|l|l|l|l|l|l|l|} 
37.- Me preocupo por los problemas de mis alumnos. & 1 & 2 & 3 & 4 & 5 & 6 & 7 \\
\hline 38.- Mis alumnos no rinden todo lo que pueden. & 1 & 2 & 3 & 4 & 5 & 6 & 7 \\
\hline 39.- Trato a todos mis alumnos por igual. & 1 & 2 & 3 & 4 & 5 & 6 & 7 \\
\hline 40.- Mis alumnos no rinden bien sus exámenes. & 1 & 2 & 3 & 4 & 5 & 6 & 7 \\
\hline $\begin{array}{l}\text { 41.- En la planificación considero capacidades y aptitudes } \\
\text { a lograr. }\end{array}$ & 1 & 2 & 3 & 4 & 5 & 6 & 7 \\
\hline $\begin{array}{l}\text { 42.- Realizó una adecuada motivación en el aula. } \\
\text { 43.- En el desarrollo de mis clases utilizo la }\end{array}$ & 1 & 2 & 3 & 4 & 5 & 6 & 7 \\
\hline $\begin{array}{l}\text { retroalimentación de mis alumnos. } \\
\text { 44.- Propicio en mis alumnos la construcción del } \\
\text { aprendizaje. }\end{array}$ & 1 & 2 & 3 & 4 & 5 & 6 & 7 \\
\hline $\begin{array}{l}\text { 45.- Las pruebas escritas que elaboró las considero } \\
\text { completas. }\end{array}$ & 1 & 2 & 3 & 4 & 5 & 6 & 7 \\
\hline $\begin{array}{l}\text { 46.- Empleo diferentes tipos de ítems al elaborar mis } \\
\text { pruebas }\end{array}$ & 1 & 2 & 3 & 4 & 5 & 6 & 7 \\
\hline $\begin{array}{l}\text { 47.- La selección de los ítems de las pruebas las efectúo en } \\
\text { base a las capacidades que deseo evaluar. }\end{array}$ & 1 & 2 & 3 & 4 & 5 & 6 & 7 \\
\hline
\end{tabular}

Nota: *ítems eliminados. 